Article

\title{
Modified Inertial-Type Multi-Choice CQ-Algorithm for Countable Weakly Relatively Non-Expansive Mappings in a Banach Space, Applications and Numerical Experiments
}

\author{
Li Wei ${ }^{1, *}$, Yibin Xin ${ }^{1}$, Ruilan Zhang ${ }^{1}$ and Ravi P. Agarwal ${ }^{2}$ \\ 1 School of Mathematics and Statistics, Hebei University of Economics and Business, Shijiazhuang 050061, \\ China; 18721063078@163.com (Y.X.); stzhangruilan@heuet.edu.cn (R.Z.) \\ 2 Department of Mathematics, Texas A \& M University-Kingsville, Kingsville, TX 78363, USA; \\ Ravi.Agarwal@tamuk.edu \\ * Correspondence: stweili@heuet.edu.cn or diandianba@yahoo.com
}

Received: 13 March 2020; Accepted: 9 April 2020; Published: 16 April 2020

check for updates

\begin{abstract}
In this paper, some new modified inertial-type multi-choice CQ-algorithms for approximating common fixed point of countable weakly relatively non-expansive mappings are presented in a real uniformly convex and uniformly smooth Banach space. New proof techniques are used to prove strong convergence theorems, which extend some previous work. The connection and application to maximal monotone operators are demonstrated. Numerical experiments are conducted to illustrate that the rate of convergence is accelerated compared to some previous ones for some special cases.
\end{abstract}

Keywords: Lyapunov functional; weakly relatively non-expansive mapping; monotone operator; inertial-type algorithm; multi-choice CQ-algorithm; common fixed point

MSC: 47H05; 47H09

\section{Introduction and Preliminaries}

In this paper, suppose $E$ is a real Banach space and $E^{*}$ is its dual space. " $u_{n} \rightarrow u^{\prime \prime}$ and " $u_{n} \rightarrow u^{\prime \prime}$ denote $\left\{u_{n}\right\}$ converges strongly or weakly to $u$, as $n \rightarrow \infty$, respectively.

A Banach space $E$ is said to be uniformly convex [1] if, for any two sequences $\left\{u_{n}\right\}$ and $\left\{v_{n}\right\}$ in $E$ such that $\left\|u_{n}\right\|=\left\|v_{n}\right\|=1$ and $\lim _{n \rightarrow \infty}\left\|u_{n}+v_{n}\right\|=2$, one has $\lim _{n \rightarrow \infty}\left\|u_{n}-v_{n}\right\|=0$.

The function $\delta_{E}:[0,+\infty) \rightarrow[0,+\infty)$ is said to be the modulus of smoothness of a Banach space $E[1]$ if it is defined as follows:

$$
\delta_{E}(t)=\sup \left\{\frac{1}{2}(\|u+v\|+\|u-v\|)-1: u, v \in E,\|u\|=1,\|v\| \leq t\right\} .
$$

A Banach space $E$ is said to be uniformly smooth [1] if $\lim _{t \rightarrow 0} \frac{\delta_{E}(t)}{t}=0$. A Banach space $E$ is said to have Property $(H)$ : if for any sequence $\left\{u_{n}\right\} \subset E$ which satisfies both $u_{n} \rightarrow u$ and $\left\|u_{n}\right\| \rightarrow\|u\|$ as $n \rightarrow \infty$, then $u_{n} \rightarrow u$, as $n \rightarrow \infty$. The uniformly convex and uniformly smooth Banach space has Property $(H)$.

The normalized duality mapping $J_{E}: E \rightarrow 2^{E^{*}}$ is defined by

$$
J_{E}(u)=\left\{g \in E^{*}:\langle u, g\rangle=\|u\|^{2}=\|g\|^{2}\right\}, u \in E,
$$

where $\langle u, g\rangle$ denotes the value of $g \in E^{*}$ at $u \in E$. 
If $E$ is a real uniformly convex and uniformly smooth Banach space, then $J_{E}$ is single-valued, surjective and $J_{E}(k u)=k J_{E}(u)$ for $u \in E$ and $k \in(0,+\infty)$. Moreover, $J_{E}^{-1}=J_{E^{*}}$ and both $J_{E}$ and $J_{E}^{-1}$ are uniformly continuous on each bounded subset of $E$ or $E^{*}$, respectively [2].

The Lyapunov functional $\varphi: E \times E \rightarrow(0,+\infty)$ is defined as follows [3]:

$$
\varphi(u, v)=\|u\|^{2}-2\left\langle u, j_{E}(v)\right\rangle+\|v\|^{2},
$$

for all $u, v \in E, j_{E}(v) \in J_{E}(v)$.

Suppose $K$ is a subset of $E$. Let $T: K \rightarrow E$ be a single-valued mapping.

(1) If $T p=p$, then $p$ is called a fixed point of $T$. The set of fixed points of $T$ is denoted by Fix $(T)$;

(2) if there exists a sequence $\left\{u_{n}\right\} \subset K$ with $u_{n} \rightarrow p \in K$ such that $u_{n}-T u_{n} \rightarrow 0$, as $n \rightarrow \infty$, then $p$ is called an asymptotic fixed point of $T$ [4]. The set of asymptotic fixed points of $T$ is denoted by $\widehat{F i x}(T)$;

(3) if there exists a sequence $\left\{u_{n}\right\} \subset K$ with $u_{n} \rightarrow p \in K$ such that $u_{n}-T u_{n} \rightarrow 0$, as $n \rightarrow \infty$, then $p$ is called a strong asymptotic fixed point of $T$ [4]. The set of strong asymptotic fixed points of $T$ is denoted by $\widehat{F i x}(T)$;

(4) $T$ is called strongly relatively non-expansive [5-7] if $\widehat{\operatorname{Fix}}(T)=\operatorname{Fix}(T) \neq \varnothing$ and $\varphi(p, T u) \leq \varphi(p, u)$ for $u \in K$ and $p \in \operatorname{Fix}(T)$;

(5) $T$ is called weakly relatively non-expansive $[4,8]$ if $\widetilde{\operatorname{Fix}}(T)=\operatorname{Fix}(T) \neq \varnothing$ and $\varphi(p, T u) \leq \varphi(p, u)$ for $u \in K$ and $p \in \operatorname{Fix}(T)$.

It is obvious that strongly relatively non-expansive mappings are weakly relatively non-expansive mappings.

If $E$ is a real reflexive, strictly convex and smooth Banach space with $K$ being its non-empty closed and convex subset, then for all $u \in E$, there exists a unique element $u_{0} \in K$ such that $\varphi\left(u_{0}, u\right)=$ $\inf \{\varphi(y, u): y \in K\}$. In this case, the generalized projection mapping $\Pi_{K}: E \rightarrow K$ is defined by $\Pi_{K} u=u_{0}$, for all $u \in E[3]$.

If $E$ is a real reflexive, strictly convex Banach space with $K$ being its non-empty closed and convex subset, then for all $u \in E$, there exists a unique element $u_{0} \in K$ such that $\left\|u-u_{0}\right\|=\inf \{\|u-y\|$ : $y \in K\}$. In this case, the metric projection mapping $P_{K}: E \rightarrow K$ is defined by $P_{K} u=u_{0}$, for all $x \in E[9]$.

In a Hilbert space $H, \Pi_{K}=P_{K}$.

$A: E \rightarrow 2^{E^{*}}$ is called monotone [10] if for all $v_{i} \in A u_{i}, i=1,2$, one has $\left\langle u_{1}-u_{2}, v_{1}-v_{2}\right\rangle \geq 0$. A is called maximal monotone if $A$ is monotone and $R\left(J_{E}+\lambda A\right)=E^{*}$, for all $\lambda>0 . x \in D(A)$ is called a zero point of $A$ if $A x=0$. The set of zero points of $A$ is denoted by $A^{-1} 0$.

In a real uniformly convex and uniformly smooth Banach $E$, the resolvent of the maximal monotone operator $A, Q_{r}^{A}$, is defined by $Q_{r}^{A} x=\left(J_{E}+r A\right)^{-1} J_{E} x$, for $x \in E$ and $r>0$. Moreover, if $A^{-1} 0 \neq \varnothing$, then $Q_{r}^{A}$ is a strongly relatively non-expansive mapping [11], and Fix $\left(Q_{r}^{A}\right)=A^{-1} 0$, for $r>0$.

Strongly relatively non-expansive mappings were introduced by Matsushita and Takahashi in 2004 (see [5-7]). The study on strongly or weakly relatively non-expansive mappings draw much attention from mathematicians until now since it includes important nonlinear mappings as special, e.g., the resolvent of a maximal monotone operator and generalized projection ([12-20]).

Recall that in 2003, Nakajo and Takahashi [21] presented the following CQ iterative algorithm to approximate the fixed point of a non-expansive mapping $T$ in a real Hilbert space $H$ :

$$
\left\{\begin{array}{l}
u_{0} \in K, \\
v_{n}=\alpha_{n} u_{n}+\left(1-\alpha_{n}\right) T u_{n}, \\
C_{n}=\left\{p \in K:\left\|v_{n}-p\right\| \leq\left\|u_{n}-p\right\|\right\}, \\
Q_{n}=\left\{p \in K:\left\langle p-u_{n}, u_{0}-u_{n}\right\rangle \leq 0\right\} \\
u_{n+1}=P_{C_{n} \cap Q_{n}}\left(u_{0}\right), \quad n \in N \cup\{0\} .
\end{array}\right.
$$


The result that $\left\{u_{n}\right\}$ converges strongly to a point in $\operatorname{Fix}(T)$ is proved.

In 2005, Matsushita and Takahashi [7] extended the topic of non-expansive mappings to that of strongly relatively non-expansive mappings. They presented the following CQ iterative algorithm to approximate the fixed points of a strongly relatively non-expansive mapping $T$ in a real uniformly convex and uniformly smooth Banach space $E$ :

$$
\left\{\begin{array}{l}
u_{0} \in K \\
v_{n}=J_{E}^{-1}\left[\alpha_{n} J_{E} u_{n}+\left(1-\alpha_{n}\right) J_{E} T u_{n}\right] \\
C_{n}=\left\{p \in K: \varphi\left(p, v_{n}\right) \leq \varphi\left(p, u_{n}\right)\right\} \\
Q_{n}=\left\{p \in K:\left\langle p-u_{n}, J_{E} u_{0}-J_{E} u_{n}\right\rangle \leq 0\right\} \\
u_{n+1}=\Pi_{C_{n} \cap Q_{n}}\left(u_{0}\right), \quad n \in N \bigcup\{0\}
\end{array}\right.
$$

The result that $\left\{u_{n}\right\}$ converges strongly to a point in $\operatorname{Fix}(T)$ is proved.

In 2009, Wei et al. [14] presented the following hybrid iterative algorithm to approximate the common fixed point of two strongly relatively non-expansive mappings $T_{1}$ and $T_{2}$ in a real uniformly convex and uniformly smooth Banach space $E$ :

$$
\left\{\begin{array}{l}
u_{0} \in K \\
v_{n}=J_{E}^{-1}\left[\alpha_{n} J_{E} u_{n}+\left(1-\alpha_{n}\right) J_{E} T_{1} u_{n}\right] \\
w_{n}=J_{E}^{-1}\left[\beta_{n} J_{E} u_{n}+\left(1-\beta_{n}\right) J_{E} T_{2} v_{n}\right] \\
C_{n}=\left\{p \in K: \varphi\left(p, w_{n}\right) \leq \beta_{n} \varphi\left(p, u_{n}\right)+\left(1-\beta_{n}\right) \varphi\left(p, v_{n}\right) \leq \varphi\left(p, u_{n}\right)\right\} \\
Q_{n}=\left\{p \in K:\left\langle p-u_{n}, J_{E} u_{0}-J_{E} u_{n}\right\rangle \leq 0\right\} \\
u_{n+1}=\Pi_{C_{n} \cap Q_{n}}\left(u_{0}\right), \quad n \in N \bigcup\{0\}
\end{array}\right.
$$

The result that $u_{n} \rightarrow \prod_{F i x\left(T_{1}\right) \cap F i x\left(T_{2}\right)}\left(u_{0}\right)$ is proved, as $n \rightarrow \infty$.

In 2010, Su et al. [8] extended the topic of strongly relatively non-expansive mappings to that for weakly relatively non-expansive mappings. They presented the following iterative algorithm for two countable families of weakly relatively non-expansive mappings $\left\{T_{n}^{(1)}\right\}$ and $\left\{T_{n}^{(2)}\right\}$ in a real uniformly convex and uniformly smooth Banach space $E$ :

$$
\left\{\begin{array}{l}
u_{0} \in K, \\
v_{n}=J_{E}^{-1}\left[\beta_{n}^{(1)} J_{E} u_{n}+\beta_{n}^{(2)} J_{E} T_{n}^{(1)} u_{n}+\beta_{n}^{(3)} J_{E} T_{n}^{(2)} u_{n}\right], \\
w_{n}=J_{E}^{-1}\left[\alpha_{n} J_{E} u_{n}+\left(1-\alpha_{n}\right) J_{E} v_{n}\right], \\
C_{n}=\left\{p \in C_{n-1} \cap Q_{n-1}: \varphi\left(p, w_{n}\right) \leq \varphi\left(p, u_{n}\right)\right\}, \\
C_{0}=\left\{p \in C: \varphi\left(p, w_{0}\right) \leq \varphi\left(p, u_{0}\right)\right\}, \\
Q_{n}=\left\{p \in C_{n-1} \cap Q_{n-1}:\left\langle p-u_{n}, J_{E} u_{0}-J_{E} u_{n}\right\rangle \leq 0\right\}, \\
Q_{0}=K, \\
u_{n+1}=\Pi_{C_{n} \cap Q_{n}}\left(u_{0}\right), \quad n \in N \bigcup\{0\} .
\end{array}\right.
$$

The result that $u_{n} \rightarrow \Pi_{\left(\cap_{n=1}^{\infty} \operatorname{Fix}\left(T_{n}^{(1)}\right)\right) \cap\left(\cap_{n=1}^{\infty} \operatorname{Fix}\left(T_{n}^{(2)}\right)\right)}\left(u_{0}\right)$ is proved, as $n \rightarrow \infty$. 
In 2019, Duan et al. [11] presented some new multi-choice iterative algorithms to approximate common fixed point of two groups of countable weakly relatively non-expansive mappings $\left\{T_{n}^{(1)}\right\}$ and $\left\{T_{n}^{(2)}\right\}$ in a real uniformly convex and uniformly smooth Banach space $E$ :

$$
\left\{\begin{array}{l}
u_{0} \in E \\
v_{n}=J_{E}^{-1}\left[\alpha_{n} J_{E} u_{n}+\left(1-\alpha_{n}\right) \sum_{i=1}^{\infty} a_{i} J_{E} T_{i}^{(1)} u_{n}\right] \\
w_{n}=J_{E}^{-1}\left[\beta_{n} J_{E} u_{n}+\left(1-\beta_{n}\right) \sum_{i=1}^{\infty} b_{i} J_{E} T_{i}^{(2)} v_{n}\right] \\
C_{1}=E=Q_{1} \\
C_{n+1}=\left\{p \in C_{n}: \varphi\left(p, v_{n}\right) \leq \varphi\left(p, u_{n}\right), \varphi\left(p, w_{n}\right) \leq \beta_{n} \varphi\left(p, u_{n}\right)+\left(1-\beta_{n}\right) \varphi\left(p, v_{n}\right)\right\}, \\
Q_{n+1}=\left\{p \in C_{n+1}:\left\|p-u_{0}\right\|^{2} \leq\left\|P_{C_{n+1}}\left(u_{0}\right)-u_{0}\right\|^{2}+\lambda_{n+1}\right\} \\
u_{n+1} \in Q_{n+1}, \quad n \in N \bigcup\{0\}
\end{array}\right.
$$

The result that $\left\{u_{n}\right\}$ converges strongly to a point in $\left(\cap_{n=1}^{\infty} \operatorname{Fix}\left(T_{n}^{(1)}\right)\right) \cap\left(\cap_{n=1}^{\infty} \operatorname{Fix}\left(T_{n}^{(2)}\right)\right)$ is proved.

Compared to the previous ones (e.g., (2)-(4)), the iterative element $u_{n+1}$ in (5) can be chosen arbitrarily in the set $Q_{n+1}$ and the metric projection $P_{C_{n+1}}\left(u_{0}\right)$ is involved instead the generalized projection.

Recall that the inertial-type algorithm was first proposed by Polyak [22] as an acceleration process in solving a smooth convex minimization problem. The inertial-type algorithm involves a two-step iterative method where the next iterate is defined by making use of the previous two iterates. Inserting an inertial term in an algorithm accelerates the rate of convergence of the iterative sequence [16]. Much devotion is contributed to the inertial-type algorithm (see [23-25] and the references therein).

In 2018, Dong et al. [26] presented the following inertial-type CQ iterative algorithm for a non-expansive mapping $T$ in a real Hilbert space $H$ :

$$
\left\{\begin{array}{l}
u_{0}, u_{1} \in H \\
w_{n}=u_{n}+\alpha_{n}\left(u_{n}-u_{n-1}\right) \\
v_{n}=\left(1-\beta_{n}\right) w_{n}+\beta_{n} T w_{n} \\
C_{n}=\left\{p \in H:\left\|v_{n}-p\right\| \leq\left\|w_{n}-p\right\|\right\} \\
Q_{n}=\left\{p \in H:\left\langle p-u_{n}, u_{0}-u_{n}\right\rangle \leq 0\right\} \\
u_{n+1}=P_{C_{n} \cap Q_{n}}\left(u_{0}\right), \quad n \in N
\end{array}\right.
$$

The result that $u_{n} \rightarrow P_{\operatorname{Fix}(T)}\left(u_{0}\right)$ is proved, as $n \rightarrow \infty$.

Motivated by Dong's work, Chidume et al. [16] presented the following inertial-type algorithm for strongly relatively non-expansive mappings $\left\{T_{i}\right\}$ in a real uniformly convex and uniformly smooth Banach space $E$ :

$$
\left\{\begin{array}{l}
u_{0}, u_{1} \in E \\
C_{0}=E \\
w_{n}=u_{n}+\alpha_{n}\left(u_{n}-u_{n-1}\right) \\
v_{n}=J_{E}^{-1}\left[(1-\beta) J_{E} w_{n}+\beta J_{E} T w_{n}\right] \\
C_{n+1}=\left\{p \in C_{n}: \varphi\left(p, v_{n}\right) \leq \varphi\left(p, w_{n}\right)\right\} \\
u_{n+1}=\prod_{C_{n+1}}\left(u_{0}\right), \quad n \in N
\end{array}\right.
$$

where $T x=J_{E}^{-1}\left(\sum_{i=1}^{\infty} a_{i}\left(b_{i} J_{E} x+\left(1-b_{i}\right) J_{E} T_{i} x\right)\right)$, for $x \in E$. The result that $u_{n} \rightarrow \Pi_{\left(\cap_{n=1}^{\infty} F i x\left(T_{n}\right)\right)}\left(u_{0}\right)$ is proved, as $n \rightarrow \infty$. 
Our paper is organized as follows: in Section 2, we shall improve a key result of Chidume [16] from strongly relatively non-expansive mappings to weakly relatively non-expansive mappings and present a new proof method. In Section 3, we shall construct some new iterative algorithms for a countable weakly relatively non-expansive mappings in a real uniformly convex and uniformly smooth Banach space and prove some strong convergence theorems. In Section 4, we shall demonstrate the applications of the new results in Section 3 to countable maximal monotone operators. In Section 5, we shall do numerical experiments to show the advantage of the newly obtained iterative algorithms in the sense that the convergence rate is accelerated compared to the previous ones for some special cases.

The following preliminaries are needed.

Lemma 1 ([15]). Assume that $E$ is a uniformly convex and also a uniformly smooth Banach space, $K$ is its non-empty closed and convex subset, $T: K \rightarrow K$ is a weakly relatively non-expansive mapping. Then Fix $(T)$ is a convex and closed subset of $E$.

Lemma 2 ([19]). Assume that $E$ is a uniformly convex and also a uniformly smooth Banach space, $\left\{x_{n}\right\}$ and $\left\{y_{n}\right\}$ are two sequences in E. If one of $\left\{x_{n}\right\}$ and $\left\{y_{n}\right\}$ is bounded and also $\varphi\left(x_{n}, y_{n}\right) \rightarrow 0$, then $x_{n}-y_{n} \rightarrow 0$, as $n \rightarrow \infty$.

Definition 1 ([27]). Assume $\left\{K_{n}\right\}$ is a sequence of non-empty closed and convex subsets of E. Then $s-$ liminf $K_{n}:=\left\{x \in E\right.$ : there exists $x_{n} \in K_{n}$ for almost all $n$ such that $x_{n} \rightarrow x$, as $\left.n \rightarrow \infty\right\}$ is called the strong lower limit of $\left\{K_{n}\right\} ; w-\limsup _{n}:=\left\{x \in E\right.$ : there exists a subsequence $K_{n_{m}}$ of $K_{n}$ such that $x_{n_{m}} \in$ $K_{n_{m}}$ for everyn $n_{m}$ and $x_{n_{m}} \rightarrow x$, as $\left.n_{m} \rightarrow \infty\right\}$ is called the weak upper limit of $\left\{K_{n}\right\}$; if $s-\liminf K_{n}=$ $w$ - limsupK $K_{n}$, the common value is denoted by $\lim _{n}$ and is called the limit of $\left\{K_{n}\right\}$.

Lemma 3 ([27]). Assume $\left\{K_{n}\right\}$ is decreasing, closed and convex in $E$, then $\lim K_{n}=\bigcap_{n=1}^{\infty} K_{n}$.

Lemma 4 ([28]). Let E be a real uniformly convex Banach space. If limK $K_{n} \neq \varnothing$, then $P_{K_{n}} x \rightarrow P_{\text {lim } K_{n}} x$, for $\forall x \in E$. Moreover, if $E$ has Property $(H)$, then $P_{K_{n}} x \rightarrow P_{\text {lim } K_{n}} x$, for for all $x \in E$.

Lemma 5 ([13]). Assume $E$ is a real uniformly convex Banach space and $r \in(0,+\infty)$. Then there exists a continuous, strictly increasing and convex function $g:[0,2 r] \rightarrow[0,+\infty)$ such that $g(0)=0$ and $\left\|\sum_{i=1}^{\infty} c_{i} x_{i}\right\|^{2} \leq \sum_{i=1}^{\infty} c_{i}\left\|x_{i}\right\|^{2}-c_{1} c_{m} g\left(\left\|x_{1}-x_{m}\right\|\right)$, for all $\left\{x_{n}\right\}_{n=1}^{\infty} \subset\{x \in E:\|x\| \leq r\},\left\{c_{n}\right\}_{n=1}^{\infty} \subset(0,1)$ with $\sum_{n=1}^{\infty} c_{n}=1$ and $m \in N$.

Lemma 6 ([10]). Assume $A: E \rightarrow 2^{E^{*}}$ is maximal monotone, then

(1) $A^{-1} 0$ is closed and convex in $E$;

(2) if $x_{n} \rightarrow x$ and $y_{n} \in A x_{n}$ with $y_{n} \rightarrow y$, or $x_{n} \rightarrow x$ and $y_{n} \in A x_{n}$ with $y_{n} \rightarrow y$, then $x \in D(A)$ and $y \in A x$.

\section{Improvement and New Proof Techniques for Chidume's Results}

Lemma 7 ([16]). Assume that $E$ is a real uniformly convex and also a uniformly smooth Banach space, $T: E \rightarrow E$ is a strongly relatively non-expansive mapping with Fix $(T) \neq \varnothing$. Let $\left\{u_{n}\right\}$ be generated by the following iterative algorithm:

$$
\left\{\begin{array}{l}
u_{0}, u_{1} \in E \\
C_{0}=E \\
w_{n}=u_{n}+\alpha_{n}\left(u_{n}-u_{n-1}\right) \\
v_{n}=J_{E}^{-1}\left[(1-\beta) J_{E} w_{n}+\beta J_{E} T w_{n}\right] \\
C_{n+1}=\left\{p \in C_{n}: \varphi\left(p, v_{n}\right) \leq \varphi\left(p, w_{n}\right)\right\} \\
u_{n+1}=\Pi_{C_{n+1}}\left(u_{0}\right), \quad n \in N
\end{array}\right.
$$


where $\alpha_{n} \in(0,1)$ and $\beta \in(0,1)$. Then $u_{n} \rightarrow \Pi_{F i x(T)}\left(u_{0}\right)$, as $n \rightarrow \infty$.

We shall improve Lemma 7 as follows:

Theorem 1. Assume that $E$ is a real uniformly convex and also a uniformly smooth Banach space, $T: E \rightarrow E$ is a weakly relatively non-expansive mapping with Fix $(T) \neq \varnothing$. Let $\left\{u_{n}\right\}$ be generated by the following iterative algorithm:

$$
\left\{\begin{array}{l}
u_{0}, u_{1} \in E \\
C_{0}=E \\
w_{n}=u_{n}+\alpha_{n}\left(u_{n}-u_{n-1}\right) \\
v_{n}=J_{E}^{-1}\left[(1-\beta) J_{E} w_{n}+\beta J_{E} T w_{n}\right] \\
C_{n+1}=\left\{p \in C_{n}: \varphi\left(p, v_{n}\right) \leq \varphi\left(p, w_{n}\right)\right\} \\
u_{n+1}=P_{C_{n+1}}\left(u_{0}\right), \quad n \in N
\end{array}\right.
$$

where $\alpha_{n} \in(0,1)$ and $\beta \in(0,1)$. Then $u_{n} \rightarrow P_{\text {Fix }(T)}\left(u_{0}\right)$, when $n \rightarrow \infty$.

Proof. We need three steps to finish the proof.

Step 1. Fix $(T) \subset C_{n}$, where $C_{n}$ is a convex and closed subset of $E$, for all $n \in N$. This ensures $\left\{u_{n}\right\}$ is well-defined.

Since $\varphi\left(p, v_{n}\right) \leq \varphi\left(p, w_{n}\right)$ is equivalent to $\left\|v_{n}\right\|^{2}-\left\|w_{n}\right\|^{2} \leq 2\left\langle p, J_{E} v_{n}-J_{E} w_{n}\right\rangle$, then $C_{n}$ is closed and convex, for $n \in N$.

For all $q \in \operatorname{Fix}(T)$, since $T$ is weakly relatively non-expansive, then

$$
\begin{aligned}
& \varphi\left(q, v_{n}\right)=\|q\|^{2}-2\left\langle q,(1-\beta) J_{E} w_{n}+\beta J_{E} T w_{n}\right\rangle+\left\|(1-\beta) J_{E} w_{n}+\beta J_{E} T w_{n}\right\|^{2} \\
& \leq(1-\beta) \varphi\left(q, w_{n}\right)+\beta \varphi\left(q, T w_{n}\right) \leq \varphi\left(q, w_{n}\right) .
\end{aligned}
$$

This ensures that $\operatorname{Fix}(T) \subset C_{n}$ for $n \in N$.

Step 2. $u_{n} \rightarrow P_{\bigcap_{n=1}^{\infty}} C_{n}\left(u_{0}\right), w_{n} \rightarrow P_{\bigcap_{n=1}^{\infty} C_{n}}\left(u_{0}\right)$ and $v_{n} \rightarrow P_{\bigcap_{n=1}^{\infty} C_{n}}\left(u_{0}\right)$, as $n \rightarrow \infty$.

It follows from Step 1 and Lemma 3 that $\lim C_{n}$ exists and $\lim C_{n}=\bigcap_{n=1}^{\infty} C_{n} \neq \varnothing$. Lemma 4 implies that $u_{n} \rightarrow P_{\bigcap_{n=1}^{\infty}} c_{n}\left(u_{0}\right)$, as $n \rightarrow \infty$. From iterative algorithm (9), one has $w_{n} \rightarrow P_{\bigcap_{n=1}^{\infty}} C_{n}\left(u_{0}\right)$, as $n \rightarrow \infty$.

Note that $P_{\bigcap_{n=1}^{\infty} C_{n}}\left(u_{0}\right) \in C_{n+1}$, then $\varphi\left(P_{\bigcap_{n=1}^{\infty} C_{n}}\left(u_{0}\right), v_{n}\right) \leq \varphi\left(P_{\bigcap_{n=1}^{\infty} C_{n}}\left(u_{0}\right), w_{n}\right) \rightarrow 0$, as $n \rightarrow \infty$. Thus Lemma 2 implies that $v_{n} \rightarrow P_{\bigcap_{n=1}^{\infty} C_{n}}\left(u_{0}\right)$, as $n \rightarrow \infty$.

Step 3. $P_{\cap_{n=1}^{\infty} C_{n}}\left(u_{0}\right)=P_{F i x(T)}\left(u_{0}\right)$.

Since Fix $(T) \subset \cap_{n=1}^{\infty} C_{n}$, then $\left\|P_{\bigcap_{n=1}^{\infty} C_{n}}\left(u_{0}\right)-u_{0}\right\| \leq\left\|P_{\text {Fix }(T)}\left(u_{0}\right)-u_{0}\right\|$. $\operatorname{Fix}(T)$.

To show that $\left\|P_{\bigcap_{n=1}^{\infty}} C_{n}\left(u_{0}\right)-u_{0}\right\| \geq\left\|P_{F i x(T)}\left(u_{0}\right)-u_{0}\right\|$, it suffices to show that $P_{\bigcap_{n=1}^{\infty} C_{n}}\left(u_{0}\right) \in$

In fact, for all $q \in \operatorname{Fix}(T)$, using Lemma 5 , one has

$$
\begin{aligned}
& \varphi\left(q, v_{n}\right)=\|q\|^{2}-2\left\langle q,(1-\beta) J_{E} w_{n}+\beta J_{E} T w_{n}\right\rangle+\left\|(1-\beta) J_{E} w_{n}+\beta J_{E} T w_{n}\right\|^{2} \\
& \leq\|q\|^{2}-2(1-\beta)\left\langle q, J_{E} w_{n}\right\rangle-2 \beta\left\langle q, J_{E} T w_{n}\right\rangle+(1-\beta)\left\|w_{n}\right\|^{2}+\beta\left\|T w_{n}\right\|^{2}-\beta(1-\beta) g\left(\left\|w_{n}-T w_{n}\right\|\right) \\
& =(1-\beta) \varphi\left(q, w_{n}\right)+\beta \varphi\left(q, T w_{n}\right)-\beta(1-\beta) g\left(\left\|w_{n}-T w_{n}\right\|\right) \\
& \leq \varphi\left(q, w_{n}\right)-\beta(1-\beta) g\left(\left\|w_{n}-T w_{n}\right\|\right) .
\end{aligned}
$$

It follows from Step 2 that, $\beta(1-\beta) g\left(\left\|w_{n}-T w_{n}\right\|\right) \leq \varphi\left(q, w_{n}\right)-\varphi\left(q, v_{n}\right) \rightarrow 0$, as $n \rightarrow \infty$. Thus $w_{n}-T w_{n} \rightarrow 0$, as $n \rightarrow \infty$. Combining with the facts that $w_{n} \rightarrow P_{\cap_{n=1}^{\infty}} C_{n}\left(u_{0}\right)$ and Lemma 1 , one has $P_{\bigcap_{n=1}^{\infty} C_{n}}\left(u_{0}\right) \in \operatorname{Fix}(T)$.

By now, we have showed that $\left\|P_{\bigcap_{n=1}^{\infty} c_{n}}\left(u_{0}\right)-u_{0}\right\|=\left\|P_{\text {Fix }(T)}\left(u_{0}\right)-u_{0}\right\|$. Since the metric projection $P_{\bigcap_{n=1}^{\infty} C_{n}}\left(u_{0}\right)$ is unique, then $P_{\bigcap_{n=1}^{\infty} C_{n}}\left(u_{0}\right)=P_{F i x(T)}\left(u_{0}\right)$. 
This completes the proof.

Remark 1. Compared to Lemma 7, three novelties can be seen in Theorem 1. One is that the discussion is extended from strongly relatively non-expansive mapping to weakly relatively non-expansive mapping. The second is that the generalized projections $\Pi_{C_{n+1}}\left(u_{0}\right)$ and $\Pi_{F i x(T)}\left(u_{0}\right)$ are replaced by the metric projections $P_{C_{n+1}}\left(u_{0}\right)$ and $P_{\text {Fix }(T)}\left(u_{0}\right)$ even if in a Banach space, which means that the computation may be easily realized theoretically. The third is that different technique is employed to show the convergence of $\left\{u_{n}\right\}$.

Lemma 8 ([12]). Assume that $E$ is a real uniformly convex and also a uniformly smooth Banach space, $T_{i}: E \rightarrow$ $E,(i \in N)$, is a sequence of countable strongly relatively non-expansive mappings with $\bigcap_{i=1}^{\infty}$ Fix $\left(T_{i}\right) \neq \varnothing$. Suppose $\left\{a_{i}\right\} \subset(0,1)$ and $\left\{b_{i}\right\} \subset(0,1)$ satisfy that $\sum_{i=1}^{\infty} a_{i}=1$. Define $T: E \rightarrow E$ as follows:

$$
T x=J_{E}^{-1}\left(\sum_{i=1}^{\infty} a_{i}\left(b_{i} J_{E} x+\left(1-b_{i}\right) J_{E} T_{i} x\right)\right),
$$

for $\forall x \in E$. The result that $T$ is strongly relatively non-expansive is true. Moreover, $F i x(T)=\bigcap_{i=1}^{\infty}$ Fix $\left(T_{i}\right)$.

Based on Lemmas 7 and 8, a countable family of strongly relatively non-expansive mapping $\left\{T_{i}\right\}_{i=1}^{\infty}$ is studied as follows:

Lemma 9 ([16]). Assume that $E, T_{i}: E \rightarrow E,\left\{a_{i}\right\},\left\{b_{i}\right\}$ and $T: E \rightarrow E$ are the same as those in Lemma 8. Let $\left\{u_{n}\right\}$ be generated by the iterative algorithm (7). Then under the assumptions that $\alpha_{n} \in(0,1)$ and $\beta \in(0,1)$, one has $u_{n} \rightarrow \Pi_{\bigcap_{i=1}^{\infty} \operatorname{Fix}\left(T_{i}\right)}\left(u_{0}\right)$, as $n \rightarrow \infty$.

Lemma 9 can be improved as follows, which is obtained directly in view of Theorem 1 and Lemma 8.

Theorem 2. Under all of the assumptions of Lemma 9, suppose $\left\{u_{n}\right\}$ is generated by the following iterative algorithm:

$$
\left\{\begin{array}{l}
u_{0}, u_{1} \in E \\
C_{0}=E \\
w_{n}=u_{n}+\alpha_{n}\left(u_{n}-u_{n-1}\right) \\
v_{n}=J_{E}^{-1}\left[(1-\beta) J_{E} w_{n}+\beta J_{E} T w_{n}\right] \\
C_{n+1}=\left\{p \in C_{n}: \varphi\left(p, v_{n}\right) \leq \varphi\left(p, w_{n}\right)\right\} \\
u_{n+1}=P_{C_{n+1}}\left(u_{0}\right), \quad n \in N .
\end{array}\right.
$$

Then $u_{n} \rightarrow P_{\bigcap_{i=1}^{\infty} \operatorname{Fix}\left(T_{i}\right)}\left(u_{0}\right)$, as $n \rightarrow \infty$.

\section{Inertial-Type Iterative Algorithms with New Set $C_{n}$}

Definition 2 ([29]). Let $E$ be a real Banach space with $K$ being its non-empty closed and convex subset. Define the function $G: K \times E^{*} \rightarrow(-\infty,+\infty)$ as follows:

$$
G(x, y)=\|x\|^{2}-2\langle x, y\rangle+\|y\|^{2}+2 \rho f(x),
$$

for all $x \in K, y \in E^{*}$, where $\rho>0$ and $f: K \rightarrow(-\infty,+\infty)$ is a proper, convex and lower-semi-continuous mapping. Obviously, if $K \equiv E$ and $f(u) \equiv 0$, then $G\left(u, J_{E} v\right) \equiv \varphi(u, v)$ for all $u, v \in E$. 
Theorem 3. Assume that $E$ is a real uniformly convex and also a uniformly smooth Banach space. Let $T_{i}^{(1)}, T_{i}^{(2)}: E \rightarrow E$ be weakly relatively non-expansive mappings, for each $i \in N$. Let $\left\{u_{n}\right\}$ be generated by the following inertial-type multi-choice iterative algorithm:

$$
\left\{\begin{array}{l}
u_{0}, u_{1} \in E, \\
v_{n}=u_{n}+t_{n}\left(u_{n}-u_{n-1}\right), \\
w_{n}=J_{E}^{-1}\left[\alpha_{n} J_{E} v_{n}+\left(1-\alpha_{n}\right) \sum_{i=1}^{\infty} a_{i} J_{E} T_{i}^{(1)} v_{n}\right], \\
y_{n}=J_{E}^{-1}\left[\beta_{n} J_{E} v_{n}+\left(1-\beta_{n}\right) \sum_{i=1}^{\infty} b_{i} J_{E} T_{i}^{(2)} w_{n}\right], \\
C_{1}=E=Q_{1}, \\
C_{n+1}=\left\{p \in C_{n}: G\left(p, J_{E} w_{n}\right) \leq G\left(p, J_{E} v_{n}\right), G\left(p, J_{E} y_{n}\right) \leq \beta_{n} G\left(p, J_{E} v_{n}\right)+\left(1-\beta_{n}\right) G\left(p, J_{E} w_{n}\right)\right\}, \\
Q_{n+1}=\left\{p \in C_{n+1}:\left\|u_{0}-p\right\|^{2} \leq\left\|P_{C_{n+1}}\left(u_{0}\right)-u_{0}\right\|^{2}+\lambda_{n+1}\right\}, \\
u_{n+1} \in Q_{n+1}, \quad n \in N,
\end{array}\right.
$$

where $G$ is the function defined in Definition 2. Under the following assumptions

(i) $\left(\bigcap_{i=1}^{\infty} \operatorname{Fix}\left(T_{i}^{(1)}\right)\right) \cap\left(\bigcap_{i=1}^{\infty} \operatorname{Fix}\left(T_{i}^{(2)}\right)\right) \neq \varnothing$;

(ii) $\left\{a_{i}\right\} \subset(0,1)$ and $\left\{b_{i}\right\} \subset(0,1)$ satisfy $\sum_{i=1}^{\infty} a_{i}=1=\sum_{i=1}^{\infty} b_{i}$;

(iii) $\left\{\lambda_{n}\right\}$ is a real number sequence in $(0,+\infty)$ with $\lambda_{n} \rightarrow 0$, as $n \rightarrow \infty$;

(iv) $\left\{\alpha_{n}\right\}$ and $\left\{\beta_{n}\right\}$ are two real number sequences in $[0,1)$ with $0 \leq \sup _{n} \alpha_{n}<1$ and $0 \leq \sup _{n} \beta_{n}<1$;

(v) $\left\{t_{n}\right\}$ is a real number sequence in $(-\infty,+\infty)$ with $t_{n} \nrightarrow \pm \infty$ as $n \rightarrow \infty$,

we have $u_{n} \rightarrow P_{\left(\bigcap_{i=1}^{\infty} \operatorname{Fix}\left(T_{i}^{(1)}\right)\right) \cap\left(\bigcap_{i=1}^{\infty} \operatorname{Fix}\left(T_{i}^{(2)}\right)\right)}\left(u_{0}\right)$, when $n \rightarrow \infty$.

Proof. We need nine steps to finish the proof.

Step 1. $\left(\bigcap_{i=1}^{\infty} \operatorname{Fix}\left(T_{i}^{(1)}\right)\right) \cap\left(\bigcap_{i=1}^{\infty} \operatorname{Fix}\left(T_{i}^{(2)}\right)\right) \subset C_{n}$, for $n \in N$.

For all $q \in\left(\bigcap_{i=1}^{\infty} \operatorname{Fix}\left(T_{i}^{(1)}\right)\right) \bigcap\left(\bigcap_{i=1}^{\infty}\right.$ Fix $\left.\left(T_{i}^{(2)}\right)\right)$, if $n=1$, it is obvious that $q \in C_{1}=E$. Noticing the definitions of Lyapunov functional and weakly relatively non-expansive mappings, one has:

$$
\begin{aligned}
& G\left(q, J_{E} w_{1}\right)=\|q\|^{2}-2\left\langle q, \alpha_{1} J_{E} v_{1}+\left(1-\alpha_{1}\right) \sum_{i=1}^{\infty} a_{i} J_{E} T_{i}^{(1)} v_{1}\right\rangle \\
& +\left\|\alpha_{1} J_{E} v_{1}+\left(1-\alpha_{1}\right) \sum_{i=1}^{\infty} a_{i} J_{E} T_{i}^{(1)} v_{1}\right\|^{2}+2 \rho f(q) \\
& \leq \alpha_{1} \varphi\left(q, v_{1}\right)+\left(1-\alpha_{1}\right) \sum_{i=1}^{\infty} a_{i} \varphi\left(q, T_{i}^{(1)} v_{1}\right)+2 \rho f(q) \\
& \leq \alpha_{1} \varphi\left(q, v_{1}\right)+\left(1-\alpha_{1}\right) \varphi\left(q, v_{1}\right)+2 \rho f(q)=G\left(q, J_{E} v_{1}\right)
\end{aligned}
$$

and

$$
\begin{aligned}
& G\left(q, J_{E} y_{1}\right) \leq\|q\|^{2}-2 \beta_{1}\left\langle q, J_{E} v_{1}\right\rangle-2\left(1-\beta_{1}\right) \sum_{i=1}^{\infty} b_{i}\left\langle q, J_{E} T_{i}^{(2)} w_{1}\right\rangle \\
& +\beta_{1}\left\|v_{1}\right\|^{2}+\left(1-\beta_{1}\right) \sum_{i=1}^{\infty} b_{i}\left\|T_{i}^{(2)} w_{1}\right\|^{2}+2 \rho f(q) \\
& =\beta_{1} \varphi\left(q, v_{1}\right)+\left(1-\beta_{1}\right) \sum_{i=1}^{\infty} b_{i} \varphi\left(q, T_{i}^{(2)} w_{1}\right)+2 \rho f(q) \\
& \leq \beta_{1} \varphi\left(q, v_{1}\right)+\left(1-\beta_{1}\right) \varphi\left(q, w_{1}\right)+2 \rho f(q) \\
& =\beta_{1} G\left(q, J_{E} v_{1}\right)+\left(1-\beta_{1}\right) G\left(q, J_{E} w_{1}\right) .
\end{aligned}
$$

Therefore, $q \in C_{2}$. That is, $\left(\bigcap_{i=1}^{\infty} \operatorname{Fix}\left(T_{i}^{(1)}\right)\right) \cap\left(\bigcap_{i=1}^{\infty} \operatorname{Fix}\left(T_{i}^{(2)}\right)\right) \subset C_{2}$.

Suppose it is true when $n \leq k$. Now, if $n=k+1$, compute the following:

$$
\begin{aligned}
& G\left(q, J_{E} w_{k+1}\right)=\|q\|^{2}-2\left\langle q, \alpha_{k+1} J_{E} v_{k+1}+\left(1-\alpha_{k+1}\right) \sum_{i=1}^{\infty} a_{i} J_{E} T_{i}^{(1)} v_{k+1}\right\rangle \\
& +\left\|\alpha_{k+1} J_{E} v_{k+1}+\left(1-\alpha_{k+1}\right) \sum_{i=1}^{\infty} a_{i} J_{E} T_{i}^{(1)} v_{k+1}\right\|^{2}+2 \rho f(q) \\
& \leq \alpha_{k+1} \varphi\left(q, v_{k+1}\right)+\left(1-\alpha_{k+1}\right) \sum_{i=1}^{\infty} a_{i} \varphi\left(q, T_{i}^{(1)} v_{k+1}\right)+2 \rho f(q) \\
& \leq \alpha_{k+1} \varphi\left(q, v_{k+1}\right)+\left(1-\alpha_{k+1}\right) \varphi\left(q, v_{k+1}\right)+2 \rho f(q)=G\left(q, J_{E} v_{k+1}\right) .
\end{aligned}
$$


Moreover,

$$
\begin{aligned}
& G\left(q, J_{E} y_{k+1}\right) \leq\|q\|^{2}-2 \beta_{k+1}\left\langle q, J_{E} v_{k+1}\right\rangle-2\left(1-\beta_{k+1}\right) \sum_{i=1}^{\infty} b_{i}\left\langle q, J_{E} T_{i}^{(2)} w_{k+1}\right\rangle \\
& +\beta_{k+1}\left\|v_{k+1}\right\|^{2}+\left(1-\beta_{k+1}\right) \sum_{i=1}^{\infty} b_{i}\left\|T_{i}^{(2)} w_{k+1}\right\|^{2}+2 \rho f(q) \\
& =\beta_{k+1} \varphi\left(q, v_{k+1}\right)+\left(1-\beta_{k+1}\right) \sum_{i=1}^{\infty} b_{i} \varphi\left(q, T_{i}^{(2)} w_{k+1}\right)+2 \rho f(q) \\
& \leq \beta_{k+1} \varphi\left(q, v_{k+1}\right)+\left(1-\beta_{k+1}\right) \varphi\left(q, w_{k+1}\right)+2 \rho f(q) \\
& =\beta_{k+1} G\left(q, J_{E} v_{k+1}\right)+\left(1-\beta_{k+1}\right) G\left(q, J_{E} w_{k+1}\right) .
\end{aligned}
$$

Therefore, $q \in C_{k+2}$. By induction, $\varnothing \neq\left(\bigcap_{i=1}^{\infty} \operatorname{Fix}\left(T_{i}^{(1)}\right)\right) \bigcap\left(\bigcap_{i=1}^{\infty} \operatorname{Fix}\left(T_{i}^{(2)}\right)\right) \subset C_{n}$, for all $n \in N$.

Step 2. $C_{n}$ is a convex and closed subset of $E$, for all $n \in N$.

If $n=1$, the result is trivial.

If $n \in N \backslash\{1\}$, then noticing the following facts: $G\left(p, J_{E} w_{n}\right) \leq G\left(p, J_{E} v_{n}\right)$ is equivalent to $2\left\langle p, J_{E} v_{n}-J_{E} w_{n}\right\rangle \leq\left\|v_{n}\right\|^{2}-\left\|w_{n}\right\|^{2}$ and $G\left(p, J_{E} y_{n}\right) \leq \beta_{n} G\left(p, J_{E} v_{n}\right)+\left(1-\beta_{n}\right) G\left(p, J_{E} w_{n}\right)$ is equivalent to $2 \beta_{n}\left\langle p, J_{E} v_{n}\right\rangle+2\left(1-\beta_{n}\right)\left\langle p, J_{E} w_{n}\right\rangle-2\left\langle p, J_{E} y_{n}\right\rangle \leq \beta_{n}\left\|v_{n}\right\|^{2}+\left(1-\beta_{n}\right)\left\|w_{n}\right\|^{2}-\left\|y_{n}\right\|^{2}$.

Thus $C_{n}$ is closed and convex, for all $n \in N$.

Step 3. $Q_{n}$ is a non-empty subset of $E, \forall n \in N$. This guarantees that $\left\{u_{n}\right\}$ is well-defined.

In fact, if $n=1$, the result is trivial.

If $n \in N \backslash\{1\}$, then we can see from the definition of metric projection that $\left\|P_{C_{n+1}}\left(u_{0}\right)-u_{0}\right\|=$ inf $f_{y \in C_{n+1}}\left\|y-u_{0}\right\|$. Then from the definition of infimum, for $\lambda_{n+1}$, there exists $\zeta_{n+1} \in C_{n+1}$ such that $\left\|u_{0}-\zeta_{n+1}\right\|^{2} \leq\left\|P_{C_{n+1}}\left(u_{0}\right)-u_{0}\right\|^{2}+\lambda_{n+1}$. This ensures that $Q_{n+1} \neq \varnothing$, for $n \in N$.

Step 4. $P_{C_{n+1}}\left(u_{0}\right) \rightarrow P_{\bigcap_{n=1}^{\infty} C_{n}}\left(u_{0}\right)$, as $n \rightarrow \infty$.

It follows from Steps 1 and 2 and Lemma 3 that $\lim C_{n}$ exists and $\lim C_{n}=\bigcap_{n=1}^{\infty} C_{n} \neq \varnothing$. Since $E$ has Property $(\mathrm{H})$, then Lemma 4 ensures that $P_{C_{n+1}}\left(u_{0}\right) \rightarrow P_{\cap_{n=1}^{\infty} C_{n}}\left(u_{0}\right)$, as $n \rightarrow \infty$.

Step 5. Both $\left\{u_{n}\right\}$ and $\left\{P_{C_{n+1}}\left(u_{0}\right)\right\}$ are bounded.

It follows from Step4 immediately that $\left\{P_{C_{n+1}}\left(u_{0}\right)\right\}$ is bounded. Since $u_{n+1} \in Q_{n+1}$, then $\| u_{0}-$ $u_{n+1}\left\|^{2} \leq\right\| P_{C_{n+1}}\left(u_{0}\right)-u_{0} \|^{2}+\lambda_{n+1}, \forall n \in N$. Since $\lambda_{n} \rightarrow 0$ and $\left\{P_{C_{n+1}}\left(u_{0}\right)\right\}$ is bounded, then it is easy to see that $\left\{u_{n}\right\}$ is bounded.

Step 6. $u_{n+1}-P_{C_{n+1}}\left(u_{0}\right) \rightarrow 0$, as $n \rightarrow \infty$.

Since $u_{n+1} \in Q_{n+1} \subset C_{n+1}$ and $C_{n}$ is convex, for $\forall t \in(0,1), t P_{C_{n+1}}\left(u_{0}\right)+(1-t) u_{n+1} \in C_{n+1}$. Noticing the definition of metric projection,

$$
\left\|P_{C_{n+1}}\left(u_{0}\right)-u_{0}\right\| \leq\left\|t P_{C_{n+1}}\left(u_{0}\right)+(1-t) u_{n+1}-u_{0}\right\|
$$

Lemma 5 ensures that

$$
\begin{aligned}
& \left\|P_{C_{n+1}}\left(u_{0}\right)-u_{0}\right\|^{2} \leq\left\|t P_{C_{n+1}}\left(u_{0}\right)+(1-t) u_{n+1}-u_{0}\right\|^{2} \\
& \leq t\left\|P_{C_{n+1}}\left(u_{0}\right)-u_{0}\right\|^{2}+(1-t)\left\|u_{n+1}-u_{0}\right\|^{2}-t(1-t) g\left(\left\|P_{C_{n+1}}\left(u_{0}\right)-u_{n+1}\right\|\right) .
\end{aligned}
$$

Thus, $\operatorname{tg}\left(\left\|P_{C_{n+1}}\left(u_{0}\right)-u_{n+1}\right\|\right) \leq\left\|u_{n+1}-u_{0}\right\|^{2}-\left\|P_{C_{n+1}}\left(u_{0}\right)-u_{0}\right\|^{2} \leq \lambda_{n+1}$. Let $t \rightarrow 1$ and later $n \rightarrow \infty$, one can see $P_{C_{n+1}}\left(u_{0}\right)-u_{n+1} \rightarrow 0$, as $n \rightarrow \infty$. $n \rightarrow \infty$.

Step 7. $u_{n} \rightarrow P_{\bigcap_{n=1}^{\infty} C_{n}}\left(u_{0}\right), v_{n} \rightarrow P_{\bigcap_{n=1}^{\infty} C_{n}}\left(u_{0}\right), w_{n} \rightarrow P_{\bigcap_{n=1}^{\infty} C_{n}}\left(u_{0}\right)$ and $y_{n} \rightarrow P_{\bigcap_{n=1}^{\infty} C_{n}}\left(u_{0}\right)$, as

In fact, it follows from Step 4 and Step 6 that $u_{n} \rightarrow P_{\bigcap_{n=1}^{\infty}} C_{n}\left(u_{0}\right)$, as $n \rightarrow \infty$. Since $v_{n}=u_{n}+$ $t_{n}\left(u_{n}-u_{n-1}\right)$, then $v_{n} \rightarrow P_{\cap_{n=1}^{\infty} C_{n}}\left(u_{0}\right)$, as $n \rightarrow \infty$. Thus $\varphi\left(u_{n+1}, v_{n}\right) \rightarrow 0$, as $n \rightarrow \infty$. 
Since $u_{n+1} \in Q_{n+1} \subset C_{n+1}$, then $G\left(u_{n+1}, J_{E} w_{n}\right) \leq G\left(u_{n+1}, J_{E} v_{n}\right)$, which implies that $\varphi\left(u_{n+1}, w_{n}\right) \leq \varphi\left(u_{n+1}, v_{n}\right) \rightarrow 0$. Lemma 2 ensures that $u_{n+1}-w_{n} \rightarrow 0$, and then $w_{n} \rightarrow P_{\bigcap_{n=1}^{\infty} C_{n}}\left(u_{0}\right)$, as $n \rightarrow \infty$.

Since $u_{n+1} \in Q_{n+1} \subset C_{n+1}$, then $G\left(u_{n+1}, J_{E} y_{n}\right) \leq \beta_{n} G\left(u_{n+1}, J_{E} v_{n}\right)+\left(1-\beta_{n}\right) G\left(u_{n+1}, J_{E} w_{n}\right)$, which implies that $\varphi\left(u_{n+1}, y_{n}\right) \leq \beta_{n} \varphi\left(u_{n+1}, v_{n}\right)+\left(1-\beta_{n}\right) \varphi\left(u_{n+1}, w_{n}\right) \rightarrow 0$, as $n \rightarrow \infty$. Thus $u_{n+1}-$ $y_{n} \rightarrow 0$, which implies that $y_{n} \rightarrow P_{\bigcap_{n=1}^{\infty} c_{n}}\left(u_{0}\right)$, as $n \rightarrow \infty$.

Step 8. $P_{\bigcap_{n=1}^{\infty} C_{n}}\left(u_{0}\right) \in\left(\bigcap_{i=1}^{\infty} \operatorname{Fix}\left(T_{i}\right)^{(1)}\right) \cap\left(\bigcap_{i=1}^{\infty} \operatorname{Fix}\left(T_{i}^{(2)}\right)\right)$.

First, we shall show that $P_{\bigcap_{n=1}^{\infty} C_{n}}\left(u_{0}\right) \in \operatorname{Fix}\left(T_{1}^{(1)}\right)$.

For all $q \in\left(\bigcap_{i=1}^{\infty} \operatorname{Fix}\left(T_{i}^{(1)}\right)\right) \cap\left(\bigcap_{i=1}^{\infty} \operatorname{Fix}\left(T_{i}^{(2)}\right)\right)$, by using Lemma 5, we have:

$$
\begin{aligned}
& \varphi\left(q, J_{E}^{-1}\left(\sum_{i=1}^{\infty} a_{i} J_{E} T_{i}^{(1)} v_{n}\right)\right)=\|q\|^{2}-2\left\langle q, \sum_{i=1}^{\infty} a_{i} J_{E} T_{i}^{(1)} v_{n}\right\rangle+\left\|\sum_{i=1}^{\infty} a_{i} J_{E} T_{i}^{(1)} v_{n}\right\|^{2} \\
& \leq\|q\|^{2}-2 \sum_{i=1}^{\infty} a_{i}\left\langle q, J_{E} T_{i}^{(1)} v_{n}\right\rangle+\sum_{i=1}^{\infty} a_{i}\left\|T_{i}^{(1)} v_{n}\right\|^{2}-a_{1} a_{m} g\left(\left\|J_{E} T_{1}^{(1)} v_{n}-J_{E} T_{m}^{(1)} v_{n}\right\|\right) \\
& =\sum_{i=1}^{\infty} a_{i} \varphi\left(q, T_{i}^{(1)} v_{n}\right)-a_{1} a_{m} g\left(\left\|J_{E} T_{1}^{(1)} v_{n}-J_{E} T_{m}^{(1)} v_{n}\right\|\right) .
\end{aligned}
$$

Then

$$
\begin{aligned}
& a_{1} a_{m} g\left(\left\|J_{E} T_{1}^{(1)} v_{n}-J_{E} T_{m}^{(1)} v_{n}\right\|\right) \leq \sum_{i=1}^{\infty} a_{i} \varphi\left(q, T_{i}^{(1)} v_{n}\right)-\varphi\left(q, J_{E}^{-1}\left(\sum_{i=1}^{\infty} a_{i} J_{E} T_{i}^{(1)} v_{n}\right)\right) \\
& \leq \varphi\left(q, v_{n}\right)-\varphi\left(q, J_{E}^{-1}\left(\sum_{i=1}^{\infty} a_{i} J_{E} T_{i}^{(1)} v_{n}\right)\right) \\
& =\left\|v_{n}\right\|^{2}-2\left\langle q, J_{E} v_{n}\right\rangle+2 \sum_{i=1}^{\infty} a_{i}\left\langle q, J_{E} T_{i}^{(1)} v_{n}\right\rangle-\left\|\sum_{i=1}^{\infty} a_{i} J_{E} T_{i}^{(1)} v_{n}\right\|^{2} .
\end{aligned}
$$

Since $w_{n}=J_{E}^{-1}\left[\alpha_{n} J_{E} v_{n}+\left(1-\alpha_{n}\right) \sum_{i=1}^{\infty} a_{i} J_{E} T_{i}^{(1)} v_{n}\right]$, then $J_{E} w_{n}-J_{E} v_{n}=(1-$ $\left.\alpha_{n}\right)\left(\sum_{i=1}^{\infty} a_{i} J_{E} T_{i}^{(1)} v_{n}-J_{E} v_{n}\right)$. Based on the properties of $J_{E}$ and $J_{E}^{-1}, w_{n} \rightarrow P_{\cap_{n=1}^{\infty} C_{n}}\left(u_{0}\right)$, $v_{n} \rightarrow P_{\bigcap_{n=1}^{\infty} C_{n}}\left(u_{0}\right)$ and $0 \leq \sup _{n} \alpha_{n}<1$, one has: $\sum_{i=1}^{\infty} a_{i} J_{E} T_{i}^{(1)} v_{n}-J_{E} v_{n} \rightarrow 0, n \rightarrow \infty$. Therefore,

$$
J_{E}^{-1}\left(\sum_{i=1}^{\infty} a_{i} J_{E} T_{i}^{(1)} v_{n}\right) \rightarrow P_{\bigcap_{n=1}^{\infty} c_{n}}\left(u_{0}\right),
$$

as $n \rightarrow \infty$. Moreover, from (12), we can also know that

$$
J_{E} T_{1}^{(1)} v_{n}-J_{E} T_{m}^{(1)} v_{n} \rightarrow 0,
$$

as $n \rightarrow \infty$, for $m \neq 1$.

Note that for all $q \in\left(\bigcap_{i=1}^{\infty} \operatorname{Fix}\left(T_{i}^{(1)}\right)\right) \cap\left(\bigcap_{i=1}^{\infty} \operatorname{Fix}\left(T_{i}^{(2)}\right)\right)$, one has $\left(\|q\|-\left\|T_{i}^{(1)} v_{n}\right\|\right)^{2} \leq$ $\varphi\left(q, T_{i}^{(1)} v_{n}\right) \leq \varphi\left(q, v_{n}\right) \leq\left(\|q\|+\left\|v_{n}\right\|\right)^{2}$. Then $\left\{T_{i}^{(1)} v_{n}\right\}$ is bounded for $\forall i \in N$. We may assume that $M=\sup \left\{\left\|T_{i}^{(1)} v_{n}\right\|: i, n \in N\right\}$.

Since $\sum_{i=1}^{\infty} a_{i}=1$, then for all $\delta>0$, there exists sufficiently large integer $N_{0}$ such that $\sum_{i=N_{0}+1}^{\infty} a_{i}<\frac{\delta}{4 M}$.

From the fact that $J_{E} T_{1}^{(1)} v_{n}-J_{E} T_{m}^{(1)} v_{n} \rightarrow 0$, as $n \rightarrow \infty$, for all $m \in\left\{1,2, \cdots, N_{0}\right\}$, we may know that there exists sufficiently large integer $M_{0}$ such that $\left\|J_{E} T_{1}^{(1)} v_{n}-J_{E} T_{m}^{(1)} v_{n}\right\|<\frac{\delta}{2}$ for all $n \geq M_{0}$ and $m \in\left\{2, \cdots, N_{0}\right\}$. Then if $n \geq M_{0}$, 


$$
\begin{aligned}
& \left\|J_{E} T_{1}^{(1)} v_{n}-\sum_{i=1}^{\infty} a_{i} J_{E} T_{i}^{(1)} v_{n}\right\| \leq \sum_{i=2}^{N_{0}} a_{i}\left\|J_{E} T_{1}^{(1)} v_{n}-J_{E} T_{i}^{(1)} v_{n}\right\|+\sum_{i=N_{0}+1}^{\infty} a_{i}\left\|J_{E} T_{1}^{(1)} v_{n}-J_{E} T_{i}^{(1)} v_{n}\right\| \\
& <\left(\sum_{i=2}^{N_{0}} a_{i}\right) \frac{\delta}{2}+\left(\sum_{i=N_{0}+1}^{\infty} a_{i}\right) 2 M<\frac{\delta}{2}+\frac{\delta}{2}=\delta .
\end{aligned}
$$

Therefore, $J_{E} T_{1}^{(1)} v_{n}-\sum_{i=1}^{\infty} a_{i} J_{E} T_{i}^{(1)} v_{n} \rightarrow 0$, as $n \rightarrow \infty$. Then (13) implies that $T_{1}^{(1)} v_{n} \rightarrow$ $P_{\bigcap_{n=1}^{\infty} C_{n}}\left(u_{0}\right)$, as $n \rightarrow \infty$. Combining with the fact that $v_{n} \rightarrow P_{\bigcap_{n=1}^{\infty} C_{n}}\left(u_{0}\right)$, and by using Lemma 1 , $P_{\bigcap_{n=1}^{\infty} C_{n}}\left(u_{0}\right) \in \operatorname{Fix}\left(T_{1}^{(1)}\right)$.

Repeating the above process for showing $P_{\bigcap_{n=1}^{\infty} C_{n}}\left(u_{0}\right) \in \operatorname{Fix}\left(T_{1}^{(1)}\right)$, we can also prove that $P_{\bigcap_{n=1}^{\infty} c_{n}}\left(u_{0}\right) \in \operatorname{Fix}\left(T_{m}^{(1)}\right), \forall m \in N$. Therefore, $P_{\bigcap_{n=1}^{\infty} C_{n}}\left(u_{0}\right) \in \bigcap_{i=1}^{\infty} \operatorname{Fix}\left(T_{i}^{(1)}\right)$.

Next, we shall show that $P_{\bigcap_{n=1}^{\infty}} c_{n}\left(u_{0}\right) \in \operatorname{Fix}\left(T_{1}^{(2)}\right)$.

For all $q \in\left(\bigcap_{i=1}^{\infty} \operatorname{Fix}\left(T_{i}^{(1)}\right)\right) \cap\left(\bigcap_{i=1}^{\infty} \operatorname{Fix}\left(T_{i}^{(2)}\right)\right)$, similar to (12), we have:

$$
\begin{aligned}
& b_{1} b_{m} g\left(\left\|J_{E} T_{1}^{(2)} w_{n}-J_{E} T_{m}^{(2)} w_{n}\right\|\right) \\
& \leq\left\|w_{n}\right\|^{2}-2\left\langle q_{,} J_{E} w_{n}\right\rangle+2 \sum_{i=1}^{\infty} b_{i}\left\langle q, J_{E} T_{i}^{(2)} w_{n}\right\rangle-\left\|\sum_{i=1}^{\infty} b_{i} J_{E} T_{i}^{(2)} w_{n}\right\|^{2} .
\end{aligned}
$$

Since $y_{n}=J_{E}^{-1}\left[\beta_{n} J_{E} v_{n}+\left(1-\beta_{n}\right) \sum_{i=1}^{\infty} b_{i} J_{E} T_{i}^{(2)} w_{n}\right]$, then $J_{E} y_{n}-J_{E} v_{n}=(1-$ $\left.\beta_{n}\right)\left(\sum_{i=1}^{\infty} b_{i} J_{E} T_{i}^{(2)} w_{n}-J_{E} v_{n}\right)$. From the facts that $v_{n} \rightarrow P_{\bigcap_{n=1}^{\infty} C_{n}}\left(u_{0}\right), y_{n} \rightarrow P_{\bigcap_{n=1}^{\infty} c_{n}}\left(u_{0}\right)$ and $0 \leq \sup _{n} \beta_{n}<1$, we have: $\sum_{i=1}^{\infty} b_{i} J_{E} T_{i}^{(2)} w_{n}-J_{E} v_{n} \rightarrow 0$, which implies that

$$
J_{E}^{-1}\left(\sum_{i=1}^{\infty} b_{i} J_{E} T_{i}^{(2)} w_{n}\right) \rightarrow P_{\bigcap_{n=1}^{\infty} C_{n}}\left(u_{0}\right)
$$

as $n \rightarrow \infty$. Coming back to (14),

$$
J_{E} T_{1}^{(2)} w_{n}-J_{E} T_{m}^{(2)} w_{n} \rightarrow 0
$$

as $n \rightarrow \infty$, for $m \neq 1$.

Similar to the above corresponding discussion, $\left\{T_{i}^{(2)} w_{n}\right\}$ is bounded for $\forall i \in N$. Then we may assume that $M^{\prime}=\sup \left\{\left\|T_{i}^{(2)} w_{n}\right\|: i, n \in N\right\}$.

Since $\sum_{i=1}^{\infty} b_{i}=1$, then for all $\delta>0$, there exists sufficiently large integer $N_{0}$ such that $\sum_{i=N_{0}+1}^{\infty} b_{i}<\frac{\delta}{4 M^{\prime}}$.

Since $J_{E} T_{1}^{(2)} w_{n}-J_{E} T_{m}^{(2)} w_{n} \rightarrow 0$, as $n \rightarrow \infty$, for all $m \in\left\{1,2, \cdots, N_{0}\right\}$, then there exists sufficiently large integer $M_{0}$ such that $\left\|J_{E} T_{1}^{(2)} w_{n}-J_{E} T_{m}^{(2)} w_{n}\right\|<\frac{\delta}{2}$ for all $n \geq M_{0}$ and $m \in\left\{2, \cdots, N_{0}\right\}$. Then if $n \geq M_{0}$,

$$
\begin{aligned}
& \left\|J_{E} T_{1}^{(2)} w_{n}-\sum_{i=1}^{\infty} b_{i} J_{E} T_{i}^{(2)} w_{n}\right\| \leq \sum_{i=2}^{N_{0}} b_{i}\left\|J_{E} T_{1}^{(2)} w_{n}-J_{E} T_{i}^{(2)} w_{n}\right\|+\sum_{i=N_{0}+1}^{\infty} b_{i}\left\|J_{E} T_{1}^{(2)} w_{n}-J_{E} T_{i}^{(2)} w_{n}\right\| \\
& <\left(\sum_{i=2}^{N_{0}} b_{i}\right) \frac{\delta}{2}+\left(\sum_{i=N_{0}+1}^{\infty} b_{i}\right) 2 M^{\prime}<\frac{\delta}{2}+\frac{\delta}{2}=\delta
\end{aligned}
$$

Therefore, $J_{E} T_{1}^{(2)} w_{n}-\sum_{i=1}^{\infty} b_{i} J_{E} T_{i}^{(2)} w_{n} \rightarrow 0$, and then (15) implies that $T_{1}^{(2)} w_{n} \rightarrow P_{\bigcap_{n=1}^{\infty}} c_{n}\left(u_{0}\right)$, as $n \rightarrow \infty$. Combining with the fact that $w_{n} \rightarrow P_{\bigcap_{n=1}^{\infty} C_{n}}\left(u_{0}\right)$, we have $P_{\cap_{n=1}^{\infty} C_{n}}\left(u_{0}\right) \in \operatorname{Fix}\left(T_{1}^{(2)}\right)$.

Repeating the above process for showing $P_{\bigcap_{n=1}^{\infty} C_{n}}\left(u_{0}\right) \in \operatorname{Fix}\left(T_{1}^{(2)}\right)$, we can also prove that $P_{\bigcap_{n=1}^{\infty} C_{n}}\left(u_{0}\right) \in \operatorname{Fix}\left(T_{m}^{(2)}\right)$, for all $m \in N$. Therefore, $P_{\bigcap_{n=1}^{\infty} C_{n}}\left(u_{0}\right) \in \bigcap_{i=1}^{\infty} \operatorname{Fix}\left(T_{i}^{(2)}\right)$.

Step 9. $P_{\bigcap_{n=1}^{\infty} C_{n}}\left(u_{0}\right)=P_{\left(\cap_{i=1}^{\infty} F i x\left(T_{i}^{(1)}\right)\right) \cap\left(\cap_{i=1}^{\infty} F i x\left(T_{i}^{(2)}\right)\right)}\left(u_{0}\right)$. 
From Steps 1 and 8, we can easily see that

$$
\left\|P_{\left(\bigcap_{i=1}^{\infty} \operatorname{Fix}\left(T_{i}^{(1)}\right)\right) \cap\left(\bigcap_{i=1}^{\infty} \operatorname{Fix}\left(T_{i}^{(2)}\right)\right)}\left(u_{0}\right)-u_{0}\right\|=\left\|P_{\bigcap_{n=1}^{\infty} C_{n}}\left(u_{0}\right)-u_{0}\right\| .
$$

Since the metric projection $P_{\cap_{n=1}^{\infty} C_{n}}\left(u_{0}\right)$ is unique, then $P_{\cap_{n=1}^{\infty} C_{n}}\left(u_{0}\right)=$ $P_{\left(\bigcap_{i=1}^{\infty} \operatorname{Fix}\left(T_{i}^{(1)}\right)\right) \cap\left(\cap_{i=1}^{\infty} \operatorname{Fix}\left(T_{i}^{(2)}\right)\right)}\left(u_{0}\right)$.

This completes the proof.

Remark 2. Compare to [16], the restriction of $\left\{t_{n}\right\}$ is weaker. Compared to [11], the construction of $C_{n}$ is different, the inertial iterate is considered and the limit of the iterative sequence is precisely defined.

Theorem 4. Assume that $E$ is a real uniformly convex and also a uniformly smooth Banach space. Let $T_{i}^{(1)}, T_{i}^{(2)}: E \rightarrow$ E be weakly relatively non-expansive mappings, for each $i \in N$. Let $\left\{u_{n}\right\}$ be generated by the following inertial-type multi-choice iterative algorithm:

$$
\left\{\begin{array}{l}
u_{0}, u_{1} \in E \\
v_{n}=u_{n}+t_{n}\left(u_{n}-u_{n-1}\right), \\
w_{n}=J_{E}^{-1}\left[\alpha_{n} J_{E} v_{1}+\left(1-\alpha_{n}\right) \sum_{i=1}^{\infty} a_{i} J_{E} T_{i}^{(1)} v_{n}\right] \\
y_{n}=J_{E}^{-1}\left[\beta_{n} J_{E} v_{1}+\left(1-\beta_{n}\right) \sum_{i=1}^{\infty} b_{i} J_{E} T_{i}^{(2)} w_{n}\right] \\
C_{1}=E=Q_{1}, \\
C_{n+1}=\left\{p \in C_{n}: G\left(p, J_{E} w_{n}\right) \leq \alpha_{n} G\left(p, J_{E} v_{1}\right)+\left(1-\alpha_{n}\right) G\left(p, J_{E} v_{n}\right)\right. \\
\left.\quad G\left(p, J_{E} y_{n}\right) \leq \beta_{n} G\left(p, J_{E} v_{1}\right)+\left(1-\beta_{n}\right) G\left(p, J_{E} w_{n}\right)\right\} \\
Q_{n+1}=\left\{p \in C_{n+1}:\left\|u_{0}-p\right\|^{2} \leq\left\|P_{C_{n+1}}\left(u_{0}\right)-u_{0}\right\|^{2}+\lambda_{n+1}\right\} \\
u_{n+1} \in Q_{n+1}, \quad n \in N .
\end{array}\right.
$$

Under the assumptions of (i)-(iii) and (v) in Theorem 3 and the following condition

$(i v)^{\prime}\left\{\alpha_{n}\right\} \subset[0,1)$ and $\left\{\beta_{n}\right\} \subset[0,1)$ with $\alpha_{n} \rightarrow 0$ and $\beta_{n} \rightarrow 0$, one has: $u_{n} \rightarrow$ $P_{\left(\bigcap_{i=1}^{\infty} \operatorname{Fix}\left(T_{i}^{(1)}\right)\right) \cap\left(\cap_{i=1}^{\infty} \operatorname{Fix}\left(T_{i}^{(2)}\right)\right)}\left(u_{0}\right)$, as $n \rightarrow \infty$.

Proof. Copy Steps 3, 4, 5, 6 and 9 in Theorem 3 and make some changes in Steps 1, 2, 7 and 8 as follows.

Step 1. $\left(\bigcap_{i=1}^{\infty} \operatorname{Fix}\left(T_{i}^{(1)}\right) \cap\left(\cap_{i=1}^{\infty} \operatorname{Fix}\left(T_{i}^{(2)}\right)\right) \subset C_{n}\right.$, for $n \in N$.

Now, for all $q \in\left(\bigcap_{i=1}^{\infty} \operatorname{Fix}\left(T_{i}^{(1)}\right) \cap\left(\cap_{i=1}^{\infty} \operatorname{Fix}\left(T_{i}^{(2)}\right)\right)\right.$.

For $n=1$, the result that $q \in C_{1}=E$ is trivial. Note the property of weakly relatively non-expansive mapping, one can get the following:

$$
\begin{aligned}
& G\left(q, J_{E} w_{1}\right)=\|q\|^{2}-2\left\langle q, \alpha_{1} J_{E} v_{1}+\left(1-\alpha_{1}\right) \sum_{i=1}^{\infty} a_{i} J_{E} T_{i}^{(1)} v_{1}\right\rangle \\
& +\left\|\alpha_{1} J_{E} v_{1}+\left(1-\alpha_{1}\right) \sum_{i=1}^{\infty} a_{i} J_{E} T_{i}^{(1)} v_{1}\right\|^{2}+2 \rho f(q) \\
& \leq\|q\|^{2}-2 \alpha_{1}\left\langle q, J_{E} v_{1}\right\rangle-2\left(1-\alpha_{1}\right) \sum_{i=1}^{\infty} a_{i}\left\langle q, J_{E} T_{i}^{(1)} v_{1}\right\rangle \\
& +\alpha_{1}\left\|v_{1}\right\|^{2}+\left(1-\alpha_{1}\right) \sum_{i=1}^{\infty} a_{i}\left\|T_{i}^{(1)} v_{1}\right\|^{2}+2 \rho f(q) \\
& =\alpha_{1} \varphi\left(q, v_{1}\right)+\left(1-\alpha_{1}\right) \sum_{i=1}^{\infty} a_{i} \varphi\left(q, T_{i}^{(1)} v_{1}\right)+2 \rho f(q) \\
& \leq \alpha_{1} \varphi\left(q, v_{1}\right)+\left(1-\alpha_{1}\right) \varphi\left(q, v_{1}\right)+2 \rho f(q)=\alpha_{1} G\left(q, J_{E} v_{1}\right)+\left(1-\alpha_{1}\right) G\left(q, J_{E} v_{1}\right)
\end{aligned}
$$

and

$$
\begin{aligned}
& G\left(q, J_{E} y_{1}\right) \leq\|q\|^{2}-2 \beta_{1}\left\langle q, J_{E} v_{1}\right\rangle-2\left(1-\beta_{1}\right) \sum_{i=1}^{\infty} b_{i}\left\langle q, J_{E} T_{i}^{(2)} w_{1}\right\rangle+\beta_{1}\left\|v_{1}\right\|^{2}+\left(1-\beta_{1}\right) \sum_{i=1}^{\infty} b_{i}\left\|T_{i}^{(2)} w_{1}\right\|^{2}+2 \rho f(q) \\
& =\beta_{1} \varphi\left(q, v_{1}\right)+\left(1-\beta_{1}\right) \sum_{i=1}^{\infty} b_{i} \varphi\left(q, T_{i}^{(2)} w_{1}\right)+2 \rho f(q) \\
& \leq \beta_{1} \varphi\left(q, v_{1}\right)+\left(1-\beta_{1}\right) \varphi\left(q, w_{1}\right)+2 \rho f(q)=\beta_{1} G\left(q, J_{E} v_{1}\right)+\left(1-\beta_{1}\right) G\left(q, J_{E} w_{1}\right) .
\end{aligned}
$$


Thus $q \in C_{2}$.

Suppose it is true when $n \leq k$. For $n=k+1$, compute the following:

$$
\begin{aligned}
& G\left(q, J_{E} w_{k+1}\right)=\|q\|^{2}-2\left\langle q, \alpha_{k+1} J_{E} v_{1}+\left(1-\alpha_{k+1}\right) \sum_{i=1}^{\infty} a_{i} J_{E} T_{i}^{(1)} v_{k+1}\right\rangle \\
& +\left\|\alpha_{k+1} J_{E} v_{1}+\left(1-\alpha_{k+1}\right) \sum_{i=1}^{\infty} a_{i} J_{E} T_{i}^{(1)} v_{k+1}\right\|^{2}+2 \rho f(q) \\
& \leq\|q\|^{2}-2 \alpha_{k+1}\left\langle q, J_{E} v_{1}\right\rangle-2\left(1-\alpha_{k+1}\right) \sum_{i=1}^{\infty} a_{i}\left\langle q, J_{E} T_{i}^{(1)} v_{k+1}\right\rangle \\
& +\alpha_{k+1}\left\|v_{1}\right\|^{2}+\left(1-\alpha_{k+1}\right) \sum_{i=1}^{\infty} a_{i}\left\|T_{i}^{(1)} v_{k+1}\right\|^{2}+2 \rho f(q) \\
& =\alpha_{k+1} \varphi\left(q, v_{1}\right)+\left(1-\alpha_{k+1}\right) \sum_{i=1}^{\infty} a_{i} \varphi\left(q, T_{i}^{(1)} v_{k+1}\right)+2 \rho f(q) \\
& \leq \alpha_{k+1} \varphi\left(q, v_{1}\right)+\left(1-\alpha_{k+1}\right) \varphi\left(q, v_{k+1}\right)+2 \rho f(q) \\
& =\alpha_{k+1} G\left(q, J_{E} v_{1}\right)+\left(1-\alpha_{k+1}\right) G\left(q, J_{E} v_{k+1}\right) .
\end{aligned}
$$

Moreover,

$$
\begin{aligned}
& G\left(q, J_{E} y_{k+1}\right) \leq\|q\|^{2}-2 \beta_{k+1}\left\langle q, J_{E} v_{1}\right\rangle-2\left(1-\beta_{k+1}\right) \sum_{i=1}^{\infty} b_{i}\left\langle q, J_{E} T_{i}^{(2)} w_{k+1}\right\rangle \\
& +\beta_{k+1}\left\|v_{1}\right\|^{2}+\left(1-\beta_{k+1}\right) \sum_{i=1}^{\infty} b_{i}\left\|T_{i}^{(2)} w_{k+1}\right\|^{2}+2 \rho f(q) \\
& =\beta_{k+1} \varphi\left(q, v_{1}\right)+\left(1-\beta_{k+1}\right) \sum_{i=1}^{\infty} b_{i} \varphi\left(q, T_{i}^{(2)} w_{k+1}\right)+2 \rho f(q) \\
& \leq \beta_{k+1} \varphi\left(q, v_{1}\right)+\left(1-\beta_{k+1}\right) \varphi\left(q, w_{k+1}\right)+2 \rho f(q) \\
& =\beta_{k+1} G\left(q, J_{E} v_{1}\right)+\left(1-\beta_{k+1}\right) G\left(q, J_{E} w_{k+1}\right) .
\end{aligned}
$$

Then $q \in C_{k+2}$. Therefore, by induction, $\varnothing \neq\left(\bigcap_{i=1}^{\infty} \operatorname{Fix}\left(T_{i}^{(1)}\right)\right) \cap\left(\bigcap_{i=1}^{\infty} \operatorname{Fix}\left(T_{i}^{(2)}\right)\right) \subset C_{n}$, for all $n \in N$.

Step 2. $C_{n}$ is a convex and closed subset of $E$.

If $n=1$, the result is trivial. If $n \in N \backslash\{1\}$, then we notice that $G\left(p, J_{E} w_{n}\right) \leq \alpha_{n} G\left(p, J_{E} v_{1}\right)+$ $\left(1-\alpha_{n}\right) G\left(p, J_{E} v_{n}\right)$ is equivalent to $2 \alpha_{n}\left\langle p, J_{E} v_{1}\right\rangle+2\left(1-\alpha_{n}\right)\left\langle p, J_{E} v_{n}\right\rangle-2\left\langle p, J_{E} w_{n}\right\rangle \leq \alpha_{n}\left\|v_{1}\right\|^{2}+(1-$ $\left.\alpha_{n}\right)\left\|v_{n}\right\|^{2}-\left\|w_{n}\right\|^{2}$ and $G\left(p, J_{E} y_{n}\right) \leq \beta_{n} G\left(p, J_{E} v_{1}\right)+\left(1-\beta_{n}\right) G\left(p, J_{E} w_{n}\right)$ is equivalent to $2 \beta_{n}\left\langle p, J_{E} v_{1}\right\rangle+$ $2\left(1-\beta_{n}\right)\left\langle p, J_{E} w_{n}\right\rangle-2\left\langle p, J_{E} y_{n}\right\rangle \leq \beta_{n}\left\|v_{1}\right\|^{2}+\left(1-\beta_{n}\right)\left\|w_{n}\right\|^{2}-\left\|y_{n}\right\|^{2}$.

Thus $C_{n}$ is closed and convex for $n \in N$.

Step 7. $u_{n} \rightarrow P_{\cap_{n=1}^{\infty} C_{n}}\left(u_{0}\right), v_{n} \rightarrow P_{\cap_{n=1}^{\infty} C_{n}}\left(u_{0}\right), w_{n} \rightarrow P_{\cap_{n=1}^{\infty} C_{n}}\left(u_{0}\right)$ and $y_{n} \rightarrow P_{\cap_{n=1}^{\infty} C_{n}}\left(u_{0}\right)$, as $n \rightarrow \infty$.

Steps 4 and 6 ensure that $u_{n} \rightarrow P_{\bigcap_{n=1}^{\infty} C_{n}}\left(u_{0}\right)$, as $n \rightarrow \infty$. Then $v_{n}=u_{n}+t_{n}\left(u_{n}-u_{n-1}\right) \rightarrow$ $P_{\cap_{n=1}^{\infty} C_{n}}\left(u_{0}\right)$, as $n \rightarrow \infty$.

Since $u_{n+1} \in Q_{n+1} \subset C_{n+1}$, then $G\left(u_{n+1}, J_{E} w_{n}\right) \leq \alpha_{n} G\left(u_{n+1}, J_{E} v_{1}\right)+\left(1-\alpha_{n}\right) G\left(u_{n+1}, J_{E} v_{n}\right)$, which ensures that $0 \leq \varphi\left(u_{n+1}, w_{n}\right) \leq \alpha_{n} \varphi\left(u_{n+1}, v_{1}\right)+\left(1-\alpha_{n}\right) \varphi\left(u_{n+1}, v_{n}\right) \rightarrow 0$, since $\alpha_{n} \rightarrow 0$, as $n \rightarrow \infty$. Employing Lemma 2, $u_{n+1}-w_{n} \rightarrow 0$ and then $w_{n} \rightarrow P_{\bigcap_{n=1}^{\infty} C_{n}}\left(u_{0}\right)$, when $n \rightarrow \infty$.

Since $u_{n+1} \in Q_{n+1} \subset C_{n+1}$, then $G\left(u_{n+1}, J_{E} y_{n}\right) \leq \beta_{n} G\left(u_{n+1}, J_{E} v_{1}\right)+\left(1-\beta_{n}\right) G\left(u_{n+1}, J_{E} w_{n}\right)$, which ensures that

$$
0 \leq \varphi\left(u_{n+1}, y_{n}\right) \leq \beta_{n} \varphi\left(u_{n+1}, v_{1}\right)+\left(1-\beta_{n}\right) \varphi\left(u_{n+1}, w_{n}\right) \rightarrow 0,
$$

since $\beta_{n} \rightarrow 0$, as $n \rightarrow \infty$. Thus $u_{n+1}-y_{n} \rightarrow 0$ and then $y_{n} \rightarrow P_{\bigcap_{n=1}^{\infty} C_{n}}\left(u_{0}\right)$, as $n \rightarrow \infty$.

Step 8. $P_{\bigcap_{n=1}^{\infty} C_{n}}\left(u_{0}\right) \in\left(\bigcap_{i=1}^{\infty} \operatorname{Fix}\left(T_{i}^{(1)}\right)\right) \cap\left(\bigcap_{i=1}^{\infty} \operatorname{Fix}\left(T_{i}^{(2)}\right)\right.$.

First, we shall show that $P_{\bigcap_{n=1}^{\infty}} U_{n}\left(u_{1}\right) \in \operatorname{Fix}\left(T_{1}^{(1)}\right)$.

For $\forall q \in\left(\bigcap_{i=1}^{\infty} \operatorname{Fix}\left(T_{i}^{(1)}\right)\right) \cap\left(\bigcap_{i=1}^{\infty} \operatorname{Fix}\left(T_{i}^{(2)}\right)\right.$, by using Lemma 5, we know that (12) in Theorem 3 is still true.

Since $w_{n}=J_{E}^{-1}\left[\alpha_{n} J_{E} v_{1}+\left(1-\alpha_{n}\right) \sum_{i=1}^{\infty} a_{i} J_{E} T_{i}^{(1)} v_{n}\right]$, then $J_{E} w_{n}-J_{E} v_{n}=\alpha_{n}\left(J_{E} v_{1}-J_{E} v_{n}\right)+$ $\left(1-\alpha_{n}\right)\left(\sum_{i=1}^{\infty} a_{i} J_{E} T_{i}^{(1)} v_{n}-J_{E} v_{n}\right)$. Noticing the properties of $J_{E}$ and $J_{E}^{-1}, v_{n} \rightarrow P_{\bigcap_{n=1}^{\infty} C_{n}}\left(u_{0}\right), w_{n} \rightarrow$ $P_{\cap_{n=1}^{\infty} C_{n}}\left(u_{0}\right)$ and $\alpha_{n} \rightarrow 0$, then $\sum_{i=1}^{\infty} a_{i} J_{E} T_{i}^{(1)} v_{n}-J_{E} v_{n} \rightarrow 0$, which implies that (13) is still true. Copy the corresponding part of Step 8 in Theorem 3, we have $P_{\bigcap_{n=1}^{\infty} C_{n}}\left(u_{0}\right) \in \operatorname{Fix}\left(T_{1}^{(1)}\right)$. 
Repeating the process for showing $P_{\bigcap_{n=1}^{\infty} C_{n}}\left(u_{0}\right) \in \operatorname{Fix}\left(T_{1}^{(1)}\right)$, we have $P_{\cap_{n=1}^{\infty} C_{n}}\left(u_{0}\right) \in$ $\operatorname{Fix}\left(T_{m}^{(1)}\right), \forall m \in N$. Therefore, $P_{\bigcap_{n=1}^{\infty} C_{n}}\left(u_{0}\right) \in \bigcap_{i=1}^{\infty} \operatorname{Fix}\left(T_{i}^{(1)}\right)$.

Next, we shall show that $P_{\bigcap_{n=1}^{\infty}}^{\infty} C_{n}\left(u_{0}\right) \in \bigcap_{i=1}^{\infty} \operatorname{Fix}\left(T_{i}^{(2)}\right)$.

For $\forall q \in\left(\bigcap_{i=1}^{\infty} \operatorname{Fix}\left(T_{i}^{(1)}\right)\right) \cap\left(\bigcap_{i=1}^{\infty} \operatorname{Fix}\left(T_{i}^{(2)}\right),(14)\right.$ is still true.

Since $y_{n}=J_{E}^{-1}\left[\beta_{n} J_{E} v_{1}+\left(1-\beta_{n}\right) \sum_{i=1}^{\infty} b_{i} J_{E} T_{i}^{(2)} w_{n}\right]$, then $J_{E} y_{n}-J_{E} v_{n}=\beta_{n}\left(J_{E} v_{1}-J_{E} v_{n}\right)+(1-$ $\left.\beta_{n}\right)\left(\sum_{i=1}^{\infty} b_{i} J_{E} T_{i}^{(2)} w_{n}-J_{E} v_{n}\right)$. From the facts that $v_{n} \rightarrow P_{\bigcap_{n=1}^{\infty} C_{n}}\left(u_{0}\right), y_{n} \rightarrow P_{\cap_{n=1}^{\infty} C_{n}}\left(u_{0}\right)$ and $\beta_{n} \rightarrow 0$, we have: $\sum_{i=1}^{\infty} b_{i} J_{E} T_{i}^{(2)} w_{n}-J_{E} v_{n} \rightarrow 0$, which implies that (15) is still true. Copy the corresponding part of Step 8 in Theorem 3, we have $P_{\bigcap_{n=1}^{\infty} C_{n}}\left(u_{0}\right) \in \operatorname{Fix}\left(T_{1}^{(2)}\right)$.

Repeating the process for showing $P_{\bigcap_{n=1}^{\infty}} C_{n}\left(u_{0}\right) \in \operatorname{Fix}\left(T_{1}^{(2)}\right)$, we can also prove that $P_{\bigcap_{n=1}^{\infty}} C_{n}\left(u_{0}\right) \in$ Fix $\left(T_{m}^{(2)}\right)$, for all $m \in N$. Therefore, $P_{\bigcap_{n=1}^{\infty} C_{n}}\left(u_{0}\right) \in \bigcap_{i=1}^{\infty} \operatorname{Fix}\left(T_{i}^{(2)}\right)$.

This completes the proof.

Using similar methods, we can get the following theorems:

Theorem 5. Assume that $E$ is a real uniformly convex and also a uniformly smooth Banach space, $T_{i}^{(1)}, T_{i}^{(2)}$ : $E \rightarrow E$ are weakly relatively non-expansive mappings, for all $i \in N$. Let $\left\{u_{n}\right\}$ be generated by the following inertial-type multi-choice iterative algorithm:

$$
\left\{\begin{array}{l}
u_{0}, u_{1} \in E \\
v_{n}=u_{n}+t_{n}\left(u_{n}-u_{n-1}\right), \\
w_{n}=J_{E}^{-1}\left[\alpha_{n} J_{E} v_{1}+\left(1-\alpha_{n}\right) \sum_{i=1}^{\infty} a_{i} J_{E} T_{i}^{(1)} v_{n}\right] \\
y_{n}=J_{E}^{-1}\left[\beta_{n} J_{E} v_{n}+\left(1-\beta_{n}\right) \sum_{i=1}^{\infty} b_{i} J_{E} T_{i}^{(2)} w_{n}\right] \\
C_{1}=E=Q_{1} \\
C_{n+1}=\left\{p \in C_{n}: G\left(p, J_{E} w_{n}\right) \leq \alpha_{n} G\left(p, J_{E} v_{1}\right)+\left(1-\alpha_{n}\right) G\left(p, J_{E} v_{n}\right),\right. \\
\left.\quad G\left(p, J_{E} y_{n}\right) \leq \beta_{n} G\left(p, J_{E} v_{n}\right)+\left(1-\beta_{n}\right) G\left(p, J_{E} w_{n}\right)\right\} \\
Q_{n+1}=\left\{p \in C_{n+1}:\left\|u_{0}-p\right\|^{2} \leq\left\|P_{U_{n+1}}\left(u_{0}\right)-u_{0}\right\|^{2}+\lambda_{n+1}\right\} \\
u_{n+1} \in Q_{n+1}, \quad n \in N .
\end{array}\right.
$$

Under the assumptions of (i)-(iii) and ( $v$ ) in Theorem 3 and the additional assumption that

$(i v)^{\prime \prime}\left\{\alpha_{n}\right\}$ and $\left\{\beta_{n}\right\}$ are two real number sequences in $[0,1)$ with $0 \leq \sup _{n} \beta_{n}<1$ and $\alpha_{n} \rightarrow 0$, $u_{n} \rightarrow P_{\left(\cap_{i=1}^{\infty} \operatorname{Fix}\left(T_{i}^{(1)}\right)\right) \cap\left(\cap_{i=1}^{\infty} \operatorname{Fix}\left(T_{i}^{(2)}\right)\right)}\left(u_{0}\right)$, when $n \rightarrow \infty$.

Theorem 6. Assume that $E$ is a real uniformly convex and also a uniformly smooth Banach space, $T_{i}^{(1)}, T_{i}^{(2)}$ : $E \rightarrow E$ are weakly relatively non-expansive mappings, for all $i \in N$. Let $\left\{u_{n}\right\}$ be generated by the following inertial-type multi-choice iterative algorithm:

$$
\left\{\begin{array}{l}
u_{0}, u_{1} \in E, \\
v_{n}=u_{n}+t_{n}\left(u_{n}-u_{n-1}\right), \\
w_{n}=J_{E}^{-1}\left[\alpha_{n} J_{E} v_{n}+\left(1-\alpha_{n}\right) \sum_{i=1}^{\infty} a_{i} J_{E} T_{i}^{(1)} v_{n}\right], \\
y_{n}=J_{E}^{-1}\left[\beta_{n} J_{E} v_{1}+\left(1-\beta_{n}\right) \sum_{i=1}^{\infty} b_{i} J_{E} T_{i}^{(2)} w_{n}\right], \\
C_{1}=E=Q_{1}, \\
C_{n+1}=\left\{p \in C_{n}: G\left(p, J_{E} w_{n}\right) \leq G\left(p, J_{E} v_{n}\right), G\left(p, J_{E} y_{n}\right) \leq \beta_{n} G\left(p, J_{E} v_{1}\right)+\left(1-\beta_{n}\right) G\left(p, J_{E} w_{n}\right)\right\}, \\
Q_{n+1}=\left\{p \in C_{n+1}:\left\|u_{0}-p\right\|^{2} \leq\left\|P_{U_{n+1}}\left(u_{0}\right)-u_{0}\right\|^{2}+\lambda_{n+1}\right\}, \\
u_{n+1} \in Q_{n+1}, \quad n \in N .
\end{array}\right.
$$

Under the assumptions of (i)-(iii) and (v) in Theorem 3 and the additional assumption that 
$(i v)^{\prime \prime \prime}\left\{\alpha_{n}\right\}$ and $\left\{\beta_{n}\right\}$ are two real number sequences in $[0,1)$ with $0 \leq \sup _{n} \alpha_{n}<1$ and $\beta_{n} \rightarrow 0$, $u_{n} \rightarrow P_{\left(\bigcap_{i=1}^{\infty} \operatorname{Fix}\left(T_{i}^{(1)}\right)\right) \cap\left(\bigcap_{i=1}^{\infty} \operatorname{Fix}\left(T_{i}^{(2)}\right)\right)}\left(u_{0}\right)$, as $n \rightarrow \infty$.

Remark 3. Replace $u_{0}$ by $u_{1}$ in the set $Q_{n+1}$ in (11), (16)-(18), we can get the corresponding results of Theorems 3-6 that $u_{n} \rightarrow P_{\left(\bigcap_{i=1}^{\infty} \operatorname{Fix}\left(T_{i}^{(1)}\right)\right) \cap\left(\cap_{i=1}^{\infty} \operatorname{Fix}\left(T_{i}^{(2)}\right)\right)}\left(u_{1}\right)$, as $n \rightarrow \infty$.

For example, modify (11) as follows:

$$
\left\{\begin{array}{l}
u_{0}, u_{1} \in E, \\
v_{n}=u_{n}+t_{n}\left(u_{n}-u_{n-1}\right), \\
w_{n}=J_{E}^{-1}\left[\alpha_{n} J_{E} v_{n}+\left(1-\alpha_{n}\right) \sum_{i=1}^{\infty} a_{i} J_{E} T_{i}^{(1)} v_{n}\right], \\
y_{n}=J_{E}^{-1}\left[\beta_{n} J_{E} v_{n}+\left(1-\beta_{n}\right) \sum_{i=1}^{\infty} b_{i} J_{E} T_{i}^{(2)} w_{n}\right], \\
C_{1}=E=Q_{1}, \\
C_{n+1}=\left\{p \in C_{n}: G\left(p, J_{E} w_{n}\right) \leq G\left(p, J_{E} v_{n}\right),\right. \\
\left.\quad G\left(p, J_{E} y_{n}\right) \leq \beta_{n} G\left(p, J_{E} v_{n}\right)+\left(1-\beta_{n}\right) G\left(p, J_{E} w_{n}\right)\right\} \\
Q_{n+1}=\left\{p \in C_{n+1}:\left\|u_{1}-p\right\|^{2} \leq\left\|P_{U_{n+1}}\left(u_{1}\right)-u_{1}\right\|^{2}+\lambda_{n+1}\right\} \\
u_{n+1} \in Q_{n+1}, \quad n \in N .
\end{array}\right.
$$
$n \rightarrow \infty$.

Under the assumptions of $(i)-(v)$ in Theorem 3, one has: $u_{n} \rightarrow P_{\left(\bigcap_{i=1}^{\infty} F i x\left(T_{i}^{(1)}\right)\right) \cap\left(\cap_{i=1}^{\infty} \operatorname{Fix}\left(T_{i}^{(2)}\right)\right)}\left(u_{1}\right)$, as

\section{Applications}

Lemma 10 ([10,11]). Assume that $E$ is a real uniformly smooth and also a uniformly convex Banach space, $A: E \rightarrow 2^{E^{*}}$ is a maximal monotone operator satisfying $A^{-1} 0 \neq \varnothing$. Then, for all $x \in E, y \in A^{-1} 0$ and $r>0$, the result $\varphi\left(y,\left(J_{E}+r A\right)^{-1} J_{E} x\right)+\varphi\left(\left(J_{E}+r A\right)^{-1} J_{E} x, x\right) \leq \varphi(y, x)$ is true.

Lemma 11 ([10,11]). If $A^{-1} 0 \neq \varnothing$, then under the assumptions of Lemma 10, one has $\left(J_{E}+r A\right)^{-1} J_{E}: E \rightarrow E$ is strongly relatively non-expansive, and Fix $\left(\left(J_{E}+r A\right)^{-1} J_{E}\right)=A^{-1} 0$, for all $r>0$.

Remark 4. Based on Lemma 11 and Theorems 3-6, we can get the following results.

Theorem 7. Assume that $E$ is a real uniformly smooth and also a uniformly convex Banach space, $T_{i}: E \rightarrow E$ are weakly relatively non-expansive mappings and $A_{i}: E \rightarrow E^{*}$ are maximal monotone operators, for all $i \in N$. Let $\left\{u_{n}\right\}$ be generated by the following inertial-type multi-choice iterative algorithm:

$$
\left\{\begin{array}{l}
u_{0}, u_{1} \in E \\
v_{n}=u_{n}+t_{n}\left(u_{n}-u_{n-1}\right), \\
w_{n}=J_{E}^{-1}\left[\alpha_{n} J_{E} v_{n}+\left(1-\alpha_{n}\right) \sum_{i=1}^{\infty} a_{i} J_{E}\left(J_{E}+r A_{i}\right)^{-1} J_{E} v_{n}\right] \\
y_{n}=J_{E}^{-1}\left[\beta_{n} J_{E} v_{n}+\left(1-\beta_{n}\right) \sum_{i=1}^{\infty} b_{i} J_{E} T_{i} w_{n}\right] \\
C_{1}=E=Q_{1} \\
C_{n+1}=\left\{p \in C_{n}: G\left(p, J_{E} w_{n}\right) \leq G\left(p, J_{E} v_{n}\right), G\left(p, J_{E} y_{n}\right) \leq \beta_{n} G\left(p, J_{E} v_{n}\right)+\left(1-\beta_{n}\right) G\left(p, J_{E} w_{n}\right)\right\} \\
Q_{n+1}=\left\{p \in C_{n+1}:\left\|u_{0}-p\right\|^{2} \leq\left\|P_{C_{n+1}}\left(u_{0}\right)-u_{0}\right\|^{2}+\lambda_{n+1}\right\} \\
u_{n+1} \in Q_{n+1}, \quad n \in N .
\end{array}\right.
$$

If $\left(\bigcap_{i=1}^{\infty} A_{i}^{-1} 0\right) \bigcap\left(\bigcap_{i=1}^{\infty}\right.$ Fix $\left.\left(T_{i}\right)\right) \neq \varnothing$, under the assumptions (ii)-(v) in Theorem 3, one has $u_{n} \rightarrow$ $P_{\left(\bigcap_{i=1}^{\infty} A_{i}^{-1} 0\right) \cap\left(\cap_{i=1}^{\infty} \operatorname{Fix}\left(T_{i}\right)\right)}\left(u_{0}\right)$, as $n \rightarrow \infty$. 
Theorem 8. Assume that $E$ is a real uniformly smooth and also a uniformly convex Banach space, $T_{i}: E \rightarrow E$ are weakly relatively non-expansive mappings and $A_{i}: E \rightarrow E^{*}$ are maximal monotone operators, for all $i \in N$. Let $\left\{u_{n}\right\}$ be generated by the following inertial-type multi-choice iterative algorithm:

$$
\left\{\begin{array}{l}
u_{0}, u_{1} \in E \\
v_{n}=u_{n}+t_{n}\left(u_{n}-u_{n-1}\right), \\
w_{n}=J_{E}^{-1}\left[\alpha_{n} J_{E} v_{1}+\left(1-\alpha_{n}\right) \sum_{i=1}^{\infty} a_{i} J_{E}\left(J_{E}+r A_{i}\right)^{-1} J_{E} v_{n}\right] \\
y_{n}=J_{E}^{-1}\left[\beta_{n} J_{E} v_{1}+\left(1-\beta_{n}\right) \sum_{i=1}^{\infty} b_{i} J_{E} T_{i} w_{n}\right] \\
C_{1}=E=Q_{1}, \\
C_{n+1}=\left\{p \in C_{n}: G\left(p, J_{E} w_{n}\right) \leq \alpha_{n} G\left(p, J_{E} v_{1}\right)+\left(1-\alpha_{n}\right) G\left(p, J_{E} v_{n}\right)\right. \\
\left.\quad G\left(p, J_{E} y_{n}\right) \leq \beta_{n} G\left(p, J_{E} v_{1}\right)+\left(1-\beta_{n}\right) G\left(p, J_{E} w_{n}\right)\right\} \\
Q_{n+1}=\left\{p \in C_{n+1}:\left\|u_{0}-p\right\|^{2} \leq\left\|P_{C_{n+1}}\left(u_{0}\right)-u_{0}\right\|^{2}+\lambda_{n+1}\right\} \\
u_{n+1} \in Q_{n+1}, \quad n \in N
\end{array}\right.
$$

If $\left(\bigcap_{i=1}^{\infty} A_{i}^{-1} 0\right) \bigcap\left(\bigcap_{i=1}^{\infty}\right.$ Fix $\left.\left(T_{i}\right)\right) \neq \varnothing$, under the assumptions $(i i),($ iii $),(i v)^{\prime}$ and $(v)$ in Theorem 4 , one has $u_{n} \rightarrow P_{\left(\bigcap_{i=1}^{\infty} A_{i}^{-1} 0\right) \cap\left(\cap_{i=1}^{\infty} \operatorname{Fix}\left(T_{i}\right)\right)}\left(u_{0}\right)$, as $n \rightarrow \infty$.

Theorem 9. Assume that $E$ is a real uniformly smooth and also a uniformly convex Banach space, $T_{i}: E \rightarrow E$ are weakly relatively non-expansive mappings and $A_{i}: E \rightarrow E^{*}$ are maximal monotone operators, for all $i \in N$. Let $\left\{u_{n}\right\}$ be generated by the following inertial-type multi-choice iterative algorithm:

$$
\left\{\begin{array}{l}
u_{0}, u_{1} \in E \\
v_{n}=u_{n}+t_{n}\left(u_{n}-u_{n-1}\right) \\
w_{n}=J_{E}^{-1}\left[\alpha_{n} J_{E} v_{1}+\left(1-\alpha_{n}\right) \sum_{i=1}^{\infty} a_{i} J_{E}\left(J_{E}+r A_{i}\right)^{-1} J_{E} v_{n}\right] \\
y_{n}=J_{E}^{-1}\left[\beta_{n} J_{E} v_{n}+\left(1-\beta_{n}\right) \sum_{i=1}^{\infty} b_{i} J_{E} T_{i} w_{n}\right] \\
C_{1}=E=Q_{1} \\
C_{n+1}=\left\{p \in C_{n}: G\left(p, J_{E} w_{n}\right) \leq \alpha_{n} G\left(p, J_{E} v_{1}\right)+\left(1-\alpha_{n}\right) G\left(p, J_{E} v_{n}\right)\right. \\
\left.\quad G\left(p, J_{E} y_{n}\right) \leq \beta_{n} G\left(p, J_{E} v_{n}\right)+\left(1-\beta_{n}\right) G\left(p, J_{E} w_{n}\right)\right\} \\
Q_{n+1}=\left\{p \in C_{n+1}:\left\|u_{0}-p\right\|^{2} \leq\left\|P_{C_{n+1}}\left(u_{0}\right)-u_{0}\right\|^{2}+\lambda_{n+1}\right\} \\
u_{n+1} \in Q_{n+1}, \quad n \in N
\end{array}\right.
$$

If $\left(\bigcap_{i=1}^{\infty} A_{i}^{-1} 0\right) \cap\left(\bigcap_{i=1}^{\infty}\right.$ Fix $\left.\left(T_{i}\right)\right) \neq \varnothing$, under the assumptions (ii), (iii), (iv)" and (v) in Theorem 5, one has $u_{n} \rightarrow P_{\left(\bigcap_{i=1}^{\infty} A_{i}^{-1} 0\right) \cap\left(\bigcap_{i=1}^{\infty} \operatorname{Fix}\left(T_{i}\right)\right)}\left(u_{0}\right)$, as $n \rightarrow \infty$.

Theorem 10. Assume that $E$ is a real uniformly smooth and also a uniformly convex Banach space, $T_{i}: E \rightarrow E$ are weakly relatively non-expansive mappings and $A_{i}: E \rightarrow E^{*}$ are maximal monotone operators, for all $i \in N$. Let $\left\{u_{n}\right\}$ be generated by the following inertial-type multi-choice iterative algorithm: 


$$
\left\{\begin{array}{l}
u_{0}, u_{1} \in E, \\
v_{n}=u_{n}+t_{n}\left(u_{n}-u_{n-1}\right), \\
w_{n}=J_{E}^{-1}\left[\alpha_{n} J_{E} v_{n}+\left(1-\alpha_{n}\right) \sum_{i=1}^{\infty} a_{i} J_{E}\left(J_{E}+r A_{i}\right)^{-1} J_{E} v_{n}\right], \\
y_{n}=J_{E}^{-1}\left[\beta_{n} J_{E} v_{1}+\left(1-\beta_{n}\right) \sum_{i=1}^{\infty} b_{i} J_{E} T_{i} w_{n}\right], \\
C_{1}=E=Q_{1}, \\
C_{n+1}=\left\{p \in C_{n}: G\left(p, J_{E} w_{n}\right) \leq G\left(p, J_{E} v_{n}\right),\right. \\
\left.\quad G\left(p, J_{E} y_{n}\right) \leq \beta_{n} G\left(p, J_{E} v_{1}\right)+\left(1-\beta_{n}\right) G\left(p, J_{E} w_{n}\right)\right\}, \\
Q_{n+1}=\left\{p \in C_{n+1}:\left\|u_{0}-p\right\|^{2} \leq\left\|P_{U_{n+1}}\left(u_{0}\right)-u_{0}\right\|^{2}+\lambda_{n+1}\right\}, \\
u_{n+1} \in Q_{n+1}, \quad n \in N .
\end{array}\right.
$$

If $\left(\bigcap_{i=1}^{\infty} A_{i}^{-1} 0\right) \cap\left(\bigcap_{i=1}^{\infty}\right.$ Fix $\left.\left(T_{i}\right)\right) \neq \varnothing$, under the assumptions (ii), (iii), (iv)'"' and (v) in Theorem 6 , one has $u_{n} \rightarrow P_{\left(\cap_{i=1}^{\infty} A_{i}^{-1} 0\right) \cap\left(\cap_{i=1}^{\infty} F i x\left(T_{i}\right)\right)}\left(u_{0}\right)$, as $n \rightarrow \infty$.

Remark 5. Similar to the discussion of Theorems 7-10 and replace $T_{i}^{(2)}$ by $\left(J_{E}+s B_{i}\right)^{-1} J_{E}$, where $B_{i}: E \rightarrow E^{*}$ is maximal monotone, we can get the following results:

Theorem 11. Assume that $E$ is a real uniformly smooth and also a uniformly convex Banach space, $A_{i}, B_{i}$ : $E \rightarrow E^{*}$ are maximal monotone operators, for all $i \in N$. Let $\left\{u_{n}\right\}$ be generated by the following inertial-type multi-choice iterative algorithm:

$$
\left\{\begin{array}{l}
u_{0}, u_{1} \in E, \\
v_{n}=u_{n}+t_{n}\left(u_{n}-u_{n-1}\right), \\
w_{n}=J_{E}^{-1}\left[\alpha_{n} J_{E} v_{n}+\left(1-\alpha_{n}\right) \sum_{i=1}^{\infty} a_{i} J_{E}\left(J_{E}+r A_{i}\right)^{-1} J_{E} v_{n}\right], \\
y_{n}=J_{E}^{-1}\left[\beta_{n} J_{E} v_{n}+\left(1-\beta_{n}\right) \sum_{i=1}^{\infty} b_{i} J_{E}\left(J_{E}+s B_{i}\right)^{-1} J_{E} w_{n}\right], \\
C_{1}=E=Q_{1} \\
C_{n+1}=\left\{p \in C_{n}: G\left(p, J_{E} w_{n}\right) \leq G\left(p, J_{E} v_{n}\right),\right. \\
\left.\quad G\left(p, J_{E} y_{n}\right) \leq \beta_{n} G\left(p, J_{E} v_{n}\right)+\left(1-\beta_{n}\right) G\left(p, J_{E} w_{n}\right)\right\}, \\
Q_{n+1}=\left\{p \in C_{n+1}:\left\|u_{0}-p\right\|^{2} \leq\left\|P_{U_{n+1}}\left(u_{0}\right)-u_{0}\right\|^{2}+\lambda_{n+1}\right\}, \\
u_{n+1} \in Q_{n+1}, \quad n \in N .
\end{array}\right.
$$

If $\left(\bigcap_{i=1}^{\infty} A_{i}^{-1} 0\right) \cap\left(\bigcap_{i=1}^{\infty} B_{i}^{-1} 0\right) \neq \varnothing$, under the assumptions (ii)-(v) in Theorem 3, one has $u_{n} \rightarrow P_{\left(\cap_{i=1}^{\infty} A_{i}^{-1} 0\right) \cap\left(\cap_{i=1}^{\infty} B_{i}^{-1} 0\right)}\left(u_{0}\right)$, as $n \rightarrow \infty$.

Theorem 12. Assume that $E$ is a real uniformly smooth and also a uniformly convex Banach space, $A_{i}, B_{i}$ : $E \rightarrow E^{*}$ are maximal monotone operators, for all $i \in N$. Let $\left\{u_{n}\right\}$ be generated by the following inertial-type multi-choice iterative algorithm: 


$$
\left\{\begin{array}{l}
u_{0}, u_{1} \in E \\
v_{n}=u_{n}+t_{n}\left(u_{n}-u_{n-1}\right) \\
w_{n}=J_{E}^{-1}\left[\alpha_{n} J_{E} v_{1}+\left(1-\alpha_{n}\right) \sum_{i=1}^{\infty} a_{i} J_{E}\left(J_{E}+r A_{i}\right)^{-1} J_{E} v_{n}\right] \\
y_{n}=J_{E}^{-1}\left[\beta_{n} J_{E} v_{1}+\left(1-\beta_{n}\right) \sum_{i=1}^{\infty} b_{i} J_{E}\left(J_{E}+s B_{i}\right)^{-1} J_{E} w_{n}\right] \\
C_{1}=E=Q_{1} \\
C_{n+1}=\left\{p \in C_{n}: G\left(p, J_{E} w_{n}\right) \leq \alpha_{n} G\left(p, J_{E} v_{1}\right)+\left(1-\alpha_{n}\right) G\left(p, J_{E} v_{n}\right)\right. \\
\left.\quad G\left(p, J_{E} y_{n}\right) \leq \beta_{n} G\left(p, J_{E} v_{1}\right)+\left(1-\beta_{n}\right) G\left(p, J_{E} w_{n}\right)\right\} \\
Q_{n+1}=\left\{p \in C_{n+1}:\left\|u_{0}-p\right\|^{2} \leq\left\|P_{U_{n+1}}\left(u_{0}\right)-u_{0}\right\|^{2}+\lambda_{n+1}\right\} \\
u_{n+1} \in Q_{n+1}, \quad n \in N .
\end{array}\right.
$$

If $\left(\bigcap_{i=1}^{\infty} A_{i}^{-1} 0\right) \cap\left(\bigcap_{i=1}^{\infty} B_{i}^{-1} 0\right) \neq \varnothing$, under the assumptions (ii), (iii), (iv)' and (v) in Theorem 4, one has $u_{n} \rightarrow P_{\left(\cap_{i=1}^{\infty} A_{i}^{-1} 0\right) \cap\left(\cap_{i=1}^{\infty} B_{i}^{-1} 0\right)}\left(u_{0}\right)$, as $n \rightarrow \infty$.

Theorem 13. Assume that $E$ is a real uniformly smooth and also a uniformly convex Banach space, $A_{i}, B_{i}$ : $E \rightarrow E^{*}$ are maximal monotone operators, for all $i \in N$. Let $\left\{u_{n}\right\}$ be generated by the following inertial-type multi-choice iterative algorithm:

$$
\left\{\begin{array}{l}
u_{0}, u_{1} \in E \\
v_{n}=u_{n}+t_{n}\left(u_{n}-u_{n-1}\right) \\
w_{n}=J_{E}^{-1}\left[\alpha_{n} J_{E} v_{1}+\left(1-\alpha_{n}\right) \sum_{i=1}^{\infty} a_{i} J_{E}\left(J_{E}+r A_{i}\right)^{-1} J_{E} v_{n}\right] \\
y_{n}=J_{E}^{-1}\left[\beta_{n} J_{E} v_{n}+\left(1-\beta_{n}\right) \sum_{i=1}^{\infty} b_{i} J_{E}\left(J_{E}+s B_{i}\right)^{-1} J_{E} w_{n}\right] \\
C_{1}=E=Q_{1} \\
C_{n+1}=\left\{p \in C_{n}: G\left(p, J_{E} w_{n}\right) \leq \alpha_{n} G\left(p, J_{E} v_{1}\right)+\left(1-\alpha_{n}\right) G\left(p, J_{E} v_{n}\right)\right. \\
\left.\quad G\left(p, J_{E} y_{n}\right) \leq \beta_{n} G\left(p, J_{E} v_{n}\right)+\left(1-\beta_{n}\right) G\left(p, J_{E} w_{n}\right)\right\} \\
Q_{n+1}=\left\{p \in C_{n+1}:\left\|u_{0}-p\right\|^{2} \leq\left\|P_{U_{n+1}}\left(u_{0}\right)-u_{0}\right\|^{2}+\lambda_{n+1}\right\} \\
u_{n+1} \in Q_{n+1}, \quad n \in N
\end{array}\right.
$$

If $\left(\bigcap_{i=1}^{\infty} A_{i}^{-1} 0\right) \cap\left(\cap_{i=1}^{\infty} B_{i}^{-1} 0\right) \neq \varnothing,(i i),(i i i),(i v)^{\prime \prime}$ and $(v)$ in Theorem 5, one has $u_{n} \rightarrow$ $P_{\left(\cap_{i=1}^{\infty} A_{i}^{-1} 0\right) \cap\left(\cap_{i=1}^{\infty} B_{i}^{-1} 0\right)}\left(u_{0}\right)$, as $n \rightarrow \infty$.

Theorem 14. Assume that $E$ is a real uniformly smooth and also a uniformly convex Banach space, $A_{i}, B_{i}$ : $E \rightarrow E^{*}$ are maximal monotone operators, for all $i \in N$. Let $\left\{u_{n}\right\}$ be generated by the following inertial-type multi-choice iterative algorithm:

$$
\left\{\begin{array}{l}
u_{0}, u_{1} \in E, \\
v_{n}=u_{n}+t_{n}\left(u_{n}-u_{n-1}\right), \\
w_{n}=J_{E}^{-1}\left[\alpha_{n} J_{E} v_{n}+\left(1-\alpha_{n}\right) \sum_{i=1}^{\infty} a_{i} J_{E}\left(J_{E}+r A_{i}\right)^{-1} J_{E} v_{n}\right], \\
y_{n}=J_{E}^{-1}\left[\beta_{n} J_{E} v_{1}+\left(1-\beta_{n}\right) \sum_{i=1}^{\infty} b_{i} J_{E}\left(J_{E}+r B_{i}\right)^{-1} J_{E} w_{n}\right], \\
C_{1}=E=Q_{1}, \\
C_{n+1}=\left\{p \in C_{n}: G\left(p, J_{E} w_{n}\right) \leq G\left(p, J_{E} v_{n}\right),\right. \\
\left.\quad G\left(p, J_{E} y_{n}\right) \leq \beta_{n} G\left(p, J_{E} v_{1}\right)+\left(1-\beta_{n}\right) G\left(p, J_{E} w_{n}\right)\right\}, \\
Q_{n+1}=\left\{p \in C_{n+1}:\left\|u_{0}-p\right\|^{2} \leq\left\|P_{U_{n+1}}\left(u_{0}\right)-u_{0}\right\|^{2}+\lambda_{n+1}\right\}, \\
u_{n+1} \in Q_{n+1}, \quad n \in N .
\end{array}\right.
$$

If $\left(\bigcap_{i=1}^{\infty} A_{i}^{-1} 0\right) \cap\left(\bigcap_{i=1}^{\infty} B_{i}^{-1} 0\right) \neq \varnothing,(i i),(i i i),(i v)^{\prime \prime \prime}$ and $(v)$ in Theorem 6 , one has 


$$
u_{n} \rightarrow P_{\left(\bigcap_{i=1}^{\infty} A_{i}^{-1} 0\right) \cap\left(\bigcap_{i=1}^{\infty} B_{i}^{-1} 0\right)}\left(u_{0}\right) \text {, as } n \rightarrow \infty .
$$

Remark 6. From Theorems 7-10, we can see that the main results of Theorems 3-6 in our paper are extensions of the corresponding results in $[11,14,19]$.

Remark 7. From Theorems 11-14, we can see that the main results of Theorems 3-6 in our paper can be further extended to the topic of designing iterative algorithms to approximate common zero points of two kinds of countable maximal monotone operators.

\section{Numerical Experiments}

In this part, some numerical experiments will be done to compare the performance of the new inertial-type iterative algorithms with non-inertial type algorithms in [11].

Example 1. Let $E=(-\infty,+\infty)$. Suppose $T_{i}^{(1)}, T_{i}^{(2)}:(-\infty,+\infty) \rightarrow(-\infty,+\infty)$ are defined as follows: $T_{1}^{(1)} x=x$ and $T_{i}^{(1)} x=\frac{5 x}{3^{i}}$ for $i \in N \backslash\{1\}$, and $T_{i}^{(2)} x=\frac{x}{2^{i}}$ for $x \in(-\infty,+\infty)$ and $i \in N$. Then $\left\{T_{i}^{(1)}\right\}$ and $\left\{T_{i}^{(2)}\right\}$ are weakly relatively non-expansive mappings such that $\left(\cap_{i=1}^{\infty} \operatorname{Fix}\left(T_{i}^{(1)}\right)\right) \cap\left(\bigcap_{i=1}^{\infty} \operatorname{Fix}\left(T_{i}^{(2)}\right)\right)=\{0\}$. Let $a_{i}=\frac{1}{2^{i}}, b_{i}=\frac{2}{3^{i}}$ for $i \in N, t_{n}=\frac{2}{n}, \alpha_{n}=\beta_{n}=\frac{1}{n}$ and $\lambda_{n+1}=\frac{1}{(n+1)^{2}}$ for $n \in N$. Then all of the conditions of Theorem 3 are satisfied for this special case.

Remark 8. Take Example 1, we can choose the following iterative sequence $\left\{u_{n}\right\}$ from infinite choices based on iterative algorithm (19) in Remark 3:

$$
\left\{\begin{array}{l}
u_{0}=1, u_{1}=2=u_{2}, \\
v_{n}=u_{n}+\frac{2}{n}\left(u_{n}-u_{n-1}\right), \quad n \in N, \\
w_{n}=\frac{2 n+1}{3 n} v_{n}, \quad n \in N, \\
y_{n}=\frac{1}{n} v_{n}+\frac{2 n-2}{5 n} w_{n}, \quad n \in N, \\
z_{n}=\frac{\frac{1}{n} v_{n}^{2}+\frac{n-1}{n} w_{n}^{2}-y_{n}^{2}}{\frac{2}{n} v_{n}+\frac{2 n-2}{n} w_{n}-2 y_{n}}, n \in N \backslash\{1\}, \\
\text { we may choose } u_{n+1}=\frac{u_{1}-\sqrt{\left(u_{1}-z_{n}\right)^{2}+\frac{1}{(n+1)^{2}}}+z_{n}}{2}, n \in N \backslash\{1\} .
\end{array}\right.
$$

With codes of Visual Basic Six, Figure $1\left(\right.$ see $\left.u_{1(n)}\right)$ is obtained.

Remark 9. Take Example 1, we can choose the following iterative sequence $\left\{u_{n}\right\}$ from infinite choices based on non-inertial type iterative algorithm (5):

$$
\left\{\begin{array}{l}
u_{1}=2, u_{2}=2, \\
v_{n}=\frac{2 n+1}{3 n} u_{n}, n \in N, \\
w_{n}=\frac{1}{n} u_{n}+\frac{2 n-2}{5 n} v_{n}, \quad n \in N, \\
z_{n}=\frac{\frac{1}{n} u_{n}^{2}+\frac{n-1}{n} v_{n}^{2}-w_{n}^{2}}{\frac{2}{n} u_{n}+\frac{2 n-2}{n} v_{n}-2 w_{n}}, n \in N \backslash\{1\}, \\
\text { we may choose } u_{n+1}=\frac{u_{1}-\sqrt{\left(u_{1}-z_{n}\right)^{2}+\frac{1}{(n+1)^{2}}}+z_{n}}{2}, n \in N \backslash\{1\} .
\end{array}\right.
$$

With codes of Visual Basic Six, Figiure 1(see $\left.u_{2(n)}\right)$ is obtained.

Remark 10. CFrom Figure 1, we may find that the inertial-type algorithm (28) converges faster than inertial-type algorithm (29) when $n$ increases. 


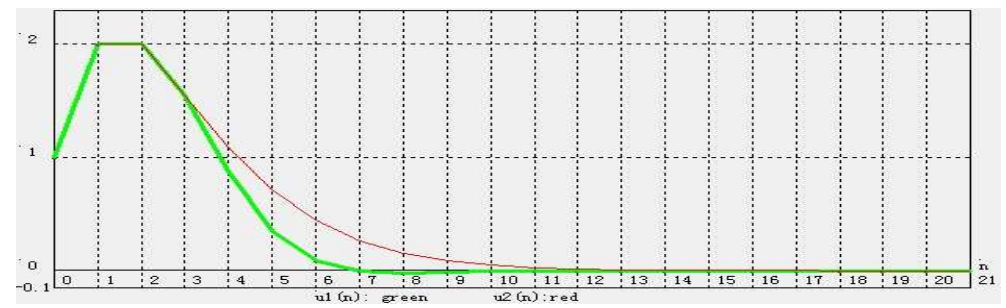

Figure 1. Convergence of $\left\{u_{n}\right\}$ in (28) (denoted by $\left\{u_{1(n)}\right\}$ ) and $\left\{u_{n}\right\}$ in (29) (denoted by $\left\{u_{2(n)}\right\}$ ).

Author Contributions: Data analysis, R.Z. and R.P.A.; Software, Y.X.; Writing-original draft, L.W. All authors have read and agreed to the published version of the manuscript.

Funding: This research was funded by "Natural Science Foundation of Hebei Province under grant number A2019207064" and "Key Project of Science and Research of Hebei Educational Department under grant number ZD2019073" and "Key Project of Science and Research of Hebei University of Economics and Business under grant number 2016KYZ07".

Acknowledgments: The first three authors were supported by Natural Science Foundation of Hebei Province under Grant No.A2019207064, Key Project of Science and Research of Hebei Educational Department under Grant No.ZD2019073, Key Project of Science and Research of Hebei University of Economics and Business under Grant No. 2016KYZ07.

Conflicts of Interest: The authors declares no conflict of interest.

\section{References}

1. Agarwal, R.P.; O’Regan, D.; Sahu, D.R. Fixed Point Theory for Lipschitz-Type Mappings with Applications; Springer: Berlin, Germany, 2008.

2. Barbu, V. Nonlinear Semigroups and Differential Equations in Banach Space; Noordhoff: Leiden, The Netherlands, 1976; pp. 10-15.

3. Alber, Y.I. Metric and generalized projection operators in Banach spaces: Properties and Applications. In Theory and Applications of Nonlinear Operators of Accretive and Monotone Type; Dekker: New York, NY, USA, 1996.

4. Zhang, J.L.; Su, Y.F.; Cheng, Q.Q. Simple projection algorithm for a countable family of weak relatively nonexpansive mappings and applications. Fixed Point Theory Appl. 2012, 2012, 205. [CrossRef]

5. Matsushita, S.Y.; Takahashi, W. An Iterative Algorithm for Relatively Nonexpansive Mappings by a Hybrid Method and Applications in Nonlinear Analysis and Convex Analysis; Yokohama Publishers: Yokohama, Japan, 2004.

6. Matsushita, S.Y.; Takahashi, W. Weak and strong convergence theorems for relatively nonexpansive mappings in Banach spaces. Fixed Point Theory Appl. 2004, 1, 37-47. [CrossRef]

7. Matsushita, S.Y.; Takahashi, W. A strong convergence theorem for relatively nonexpansive mappings in a Banach space. J. Approx. Theory. 2005, 134, 257-266. [CrossRef]

8. Su, Y.F.; Xu, H.K.; Zhang, X. Strong convergence theorems for two countable families of weak relatively nonexpansive mappings and applications. Nonlinear Appl. 2010, 73, 3890-3906. [CrossRef]

9. Takahashi, W. Nonlinear Functional Analysis; Yokohama Publishers: Yokohama, Japan, 2000.

10. Pascali, D.; Sburlan, S. Nonlinear Mappings of Monotone Type; Sijthoff and Noordhoff International Publishers: Alphen aan den Rijn, The Netherlands, 1978.

11. Duan, L.L.; Shi, A.F.; Wei, L.; Agarwal, R.P. Construction techniques of projection sets in hybrid methods for infinite weakly relatively nonexpansive mappings with applications. J. Nonlinear Funct. Anal. 2019, $2019,14$.

12. Kohsaka, F.; Takahashi, W. The Set of Common Fixed Points of an Infinite Family of Relatively Nonexpansive Mappings in Banach and Function Spaces II; Yokohama Publishers: Yokohama, Japan, 2008.

13. Nilsrakoo, W.; Saejung, S. On the fixed-point set of a family of relatively nonexpansive and generalized nonexpansive mappings. Fixed Point Theory Appl. 2010, 2010, 414232. [CrossRef]

14. Wei, L.; Cho, Y.J.; Zhou, H.Y. A strong convergence theorem for common fixed points of two relatively nonexpansive mappings and its applications. J. Appl. Math. Comput. 2009, 29, 95-103. [CrossRef]

15. Zhang, J.; Su, Y.; Cheng, Q. Hybrid algorithm of fixed point for weak relatively nonexpansive multivalued mappings and applications. Abstr. Appl. Anal. 2012, 2012, 479438. [CrossRef] 
16. Chidume, C.E.; Ikechukwu, S.I.; Adamu, A. Inertial algorithm for approximating a common fixed point for a countable family of relatively nonexpansive maps. Fixed Point Theory Appl. 2018, 2018, 9. [CrossRef]

17. Gala, S.; Ragusa, M.A. Logarithmically improved regularity criterion for the Boussinesq equations in Besov spaces with negative indices. Appl. Anal. 2016, 95, 1271-1279. [CrossRef]

18. Wei, L.; Agarwal, R.P. Simple form of a projection set in hybrid iterative schemes for non-linear mappings, application of inequalities and computational experiments. J. Inequal. Appl. 2018, 2018, 179. [CrossRef] [PubMed]

19. Wei, L.; Agarwal, R.P. New construction and proof techniques of projection algorithms for countable maximal monotone mappings and weakly relatively non-expansive mappings in a Banach space. J. Inequal. Appl. 2018, 2018, 64. [CrossRef] [PubMed]

20. Saleem, N.; Vujakovic, J.; Baloch, W.U.; Radenovic, S. Coincidence point results for multivalued Suzuki type mappings using contraction in b-metric spaces. Mathematics 2019, 7, 1017 [CrossRef]

21. Nakajo, K.; Takahashi, W. Strong convergence theorems for nonexpansive mappings and nonexpansive semigroups. J. Math. Anal. 2003, 279, 372-379. [CrossRef]

22. Polyak, B.T. Some methods of speeding up the convergence of iteration methods. USSR Comput. Math. Math. Phys. 1964, 4, 1-17. [CrossRef]

23. Tian, M.; Jiang, B.N. Inertial hybrid algorithm for variational inequality problems in Hilbert spaces. J. Inequal. Appl. 2020, 2020, 12. [CrossRef]

24. Bot, R.I.; Csetnek, E.R.; Hendrich, C. Inertial Douglas-Rachford splitting for monotone inclusion problems. Appl. Math. Comput. 2015, 256, 472-487.

25. Lorena, D.A.; Pock, T. An inertial forward-backward algorithm for monotone inclusions. J. Math. Imaging Vis. 2015, 51, 311-325. [CrossRef]

26. Dong, Q.L.; Yuan, H.B.; Cho, Y.J.; Rassias, T.M. Modified inertial Mann algorithm and inertial CQ-algorithm for nonexpansive mappings. Optim. Lett. 2018, 12, 87-102. [CrossRef]

27. Mosco, U. Convergence of convex sets and of solutions of variational inequalities. Adv. Math. 1969, 3, 510-585. [CrossRef]

28. Tsukada, M. Convergence of best approximations in a smooth Banach space. J. Approx. Theory. 1984, 40, 301-309. [CrossRef]

29. Zhang, J.L.; Su, Y.F.; Xu, H.K.; Cheng, Q.Q. Strong convergence theorems for a common fixed point of two countable families of relatively quasi nonexpansive mappings and applications. Abstr. Appl. Anal. 2012, 2012, 956950. [CrossRef]

(C) 2020 by the authors. Licensee MDPI, Basel, Switzerland. This article is an open access article distributed under the terms and conditions of the Creative Commons Attribution (CC BY) license (http://creativecommons.org/licenses/by/4.0/). 